\title{
La producción de agua desalinizada en las regiones de Murcia y Valencia. Balance de un recurso alternativo con luces y sombras*
}

\author{
Álvaro Francisco Morote Seguido \\ Antonio Manuel Rico Amorós \\ Enrique Moltó Mantero \\ Universidad de Alicante. Instituto Interuniversitario de Geografía \\ alvaro.morote@ua.es \\ am.rico@ua.es \\ enrique.molto@ua.es
}

\section{Resumen}

El litoral de las regiones de Murcia y Valencia ha sufrido grandes transformaciones territoriales durante las últimas décadas, debido a la fuerte expansión de las funciones residenciales, turísticas y de servicios. El Plan Hidrológico Nacional (2001) y, en mayor medida, el Programa A.G.U.A. (2004) apostaron por la desalinización de agua marina a gran escala para garantizar demandas urbanas, turísticas e incluso agrícolas. La paralización de los planes urbanísticos provocada por la crisis financiera (2007), unida a la tendencia de reducción del consumo de agua potable de la última década, evidencian una capacidad de producción de agua desalinizada muy superior a las necesidades del momento presente. Esta investigación revisa la situación actual de la desalinización de agua marina y salobre continental en las regiones de Murcia y Valencia, hace balance de sus ventajas e inconvenientes y plantea una discusión en torno al papel que puede desempeñar esta fuente no convencional como recurso estratégico y de futuro para garantizar demandas urbano-turísticas y agrícolas, principalmente durante situaciones de sequía.

Palabras clave: desalinización; consumo; agua; Valencia; Murcia

* El presente artículo se inserta en los proyectos de investigación Urbanización y metabolismo hidrico en el litoral de Alicante: Análisis de tendencias para el periodo 2000-2010 (CSO201236997-CO2-02), financiado por el Ministerio de Ciencia y Tecnología, y Usos y gestión de recursos hidricos no convencionales en el litoral de las regiones de Valencia y Murcia como estrategia de adaptación a la sequía (CSO2015-65182-C2-2-P), financiado por el Ministerio de Economía y Competitividad. También recoge resultados de una beca predoctoral de Formación de Profesorado Universitario, del Programa Nacional de Investigación Científica, Desarrollo e Innovación Tecnológica (FPU). 
Resum. La producció d'aigua dessalinitzada a les regions de Múrcia $i$ València: Balanç d'un recurs alternatiu amb llums i ombres

El litoral de les regions de Múrcia i València ha patit grans transformacions territorials durant les últimes dècades, a causa de la forta expansió de les funcions residencials, turístiques i de servicis. El Pla Hidrològic Nacional (2001) i, en major grau, el Programa A.G.U.A. (2004) van apostar per la dessalinització d'aigua marina a gran escala per a garantir demandes urbanes, turístiques i inclús agrícoles. La paralització dels plans urbanístics provocada per la crisi financera (2007), junt amb la tendència de reducció del consum d'aigua potable de l'última dècada, evidencien una capacitat de producció d'aigua dessalinitzada molt superior a les necessitats del moment present. Esta investigació revisa la situació actual de la dessalinització d'aigua marina i salobre continental en les regions de Múrcia i València, fa balanç dels avantatges i dels inconvenients que comporta i planteja una discussió entorn del paper que pot exercir esta font no convencional com a recurs estratégic i de futur per a garantir demandes urbano-turístiques i agrícoles, principalment durant situacions de sequera.

Paraules clau: dessalinització; consum; aigua; València; Múrcia

Résumé. La production d'eau dessalée dans les régions de Murcia et de Valencia: Évaluation en clair obscur d'une ressource alternative

Les régions côtières de Murcia et de Valencia ont subi d'importantes transformations territoriales au cours des dernières décennies en raison de la forte expansion des fonctions résidentielles, touristiques et des services. Le Plan Hidrológico Nacional (2001) et notamment, le Programa A.G.U.A. (2004) ont parié sur le dessalement d'eau de mer à grande échelle pour répondre aux demandes urbaine, touristique et rurale. L'interruption des plans urbains provoquée par la crise financière (2007), s'ajoutant à une réduction de la consommation d'eau potable à partir de la dernière décennie mettent en évidence une capacité de production d'eau dessalée supérieure aux besoins actuels. Cette étude passe en revue l'état actuel du dessalement d'eau de mer et saumâtre dans les régions de Murcia et de Valencia. Il fait aussi un équilibre des avantages et des inconvénients et présente une discussion sur le rôle que cette source non conventionnelle stratégique et d'avenir peut jouer pour répondre aux demances urbaine, touristique et rurale, particulièrement en période de sécheresse.

Mots-clés: dessalement; consommation; eau; Valencia; Murcia

Abstract. Desalinated water production in the regions of Murcia and Valencia: Assessment of an alternative resource with highs and lows

The coast of the regions of Murcia and Valencia has undergone important land use changes in recent decades due to the intense expansion of tourism activity and residential and services uses. In general, the Spanish National Hydrological Plan of 2001, and especially the A.G.U.A. Program of 2004, supported large-scale water desalination to guarantee urban, tourism and rural water demand. The end of the urban sprawl due to the economic crisis, in addition to the decrease in drinking water consumption in the last decade, have resulted in a desalination water production capacity that is higher than current needs. This research reviews the current status of desalination water (from the sea and underground) in the regions of Murcia and Valencia. Moreover, it takes stock of its advantages and disadvantages, and discusses the role that this strategic and unconventional resource could play in the future to ensure urban, tourism and rural demands, especially during droughts.

Keywords: desalination; consumption; water; Valencia; Murcia 


\section{Sumario \\ 1. Introducción 4. Conclusiones \\ 2. Producción y consumo \\ Agradecimientos \\ de agua desalinizada \\ Referencias bibliográficas}

3. Discusión: ¿Una fuente alternativa a los recursos convencionales?

\section{Introducción}

Desde las décadas de 1960 y 1970, el litoral mediterráneo español y, en particular, las costas de Murcia y Valencia han sufrido importantes transformaciones territoriales gracias a la implantación de la actividad turística y de las funciones residenciales como motor de desarrollo económico de estas regiones (Rico, 2007; Hernández, 2013). Una de las principales consecuencias ha sido el incremento de la superficie urbanizada y de población (Gaja, 2008; Piqueras, 2012; Morote y Hernández, 2016). En este sentido, no cabe olvidar que España es el segundo país en recepción de visitantes en el contexto internacional (Vera, 2006). Ligado a ello, la demanda de determinados recursos, como es el caso del agua, ha ido en aumento para atender a los consumos urbano-turísticos (Rico et al., 2009; Hernández et al., 2010; Cole, 2014; Gössling, 2015). Por ello, el agua es un elemento de vital importancia que ha condicionado el desarrollo socioeconómico, particularmente en las comarcas que se adscriben a la región climática del sureste ibérico, caracterizada por la escasez de recursos hídricos y por la elevada exposición física frente a las sequías (Monreal, 2001; Gil y Rico, 2007). Este es un hecho que no solo afecta a estas regiones, sino que es similar en otras áreas españolas (Raya y Benítez, 2002; Domene y Saurí, 2006; Albert y Rullán, 2007; García, 2014; Hof y Wolf, 2014) y del resto del mundo con condiciones climáticas parecidas y con modelos de urbanización similares (Loh y Coghlan, 2003; Troy y Holloway, 2004; Fernández y Barrado, 2011).

Este crecimiento de viviendas se ha traducido en un incremento de la demanda de agua potable hasta alcanzar valores máximos históricos en los años previos al estallido de la crisis económica e inmobiliaria (2007-2008). En este sentido, tanto en los planes hidrológicos de cuenca como en los propios planes generales de los municipios, se preveía que la población, el número de viviendas y, por tanto, la demanda de agua, se incrementarían y que, además, el abastecimiento no se garantizaría con los recursos hídricos disponibles, teniendo en cuenta episodios futuros de sequías y el Cambio Climático (Olcina, 2002; Vera, 2006, March et al., 2014). En este sentido, el Grupo Intergubernamental de Expertos sobre el Cambio Climático (IPCC) presenta la desalinización como una opción potencial, junto a la reutilización de aguas residuales, para adaptarse a los impactos del Cambio Climático, especialmente en las regiones áridas y semiáridas. Por lo tanto, la desalinización, como indican Baldwin y Uhlman (2010), puede contribuir a mejorar la seguridad del agua y puede 
convertirse en una fuente de recursos segura a largo plazo, con la flexibilidad de que su producción pueda descender en el caso de que abunden otras fuentes de recursos e incrementarse ante episodios de sequías.

Durante los últimos años, se ha reforzado la idea de que la gestión del agua debe de entenderse como un instrumento al servicio de una política territorial explícita y que esta, además, se vea respaldada por la creciente demanda de integración entre gestión del agua y políticas sectoriales, concepto clave de la actual Directiva Marco del Agua (Del Moral, 2009). En España, los proyectos hidráulicos del siglo $\mathrm{xx}$, se han referido con el término de "paradigma hidraúlico», con la finalidad de dar soluciones para proporcionar agua subvencionada para riego y abastecimiento urbano (Saurí y Del Moral, 2001; Kallis y Coccossis, 2003). Los crecientes problemas en términos ambientales, sociales y económicos de soluciones convencionales como embalses y trasvases habrían motivado un replanteamiento general de estas soluciones, tal y como se puso de manifiesto en el Plan Hidrológico Nacional español de 2001 y la fuerte oposición que suscitó su principal proyecto como era el trasvase del río Ebro (Saurí, 2003). Ejemplos de dichos debates creados por grandes infraestructuras hídricas abundan a nivel internacional. En California (EE. UU.), a lo largo de su historia, se ha rechazado la desalinización, ya que se obtiene el agua del río Colorado y de los acuíferos de forma mucho más barata, y ello debe sumarse a las grandes subvenciones del Estado. Sin embargo, conforme las sequías y la explotación irracional de sus recursos subterráneos han planteado problemas de suministro, han empezado a funcionar desalinizadoras por todo el Estado. A ello contribuye el avance de la tecnología, lo que permite que el agua desalinizada sea cada vez más competitiva, necesite menor consumo energético y provoque menos costes ambientales. En América Latina, son conocidos los impactos y los conflictos derivados de los megaproyectos hídricos (Boelens et al., 2012; Latta y Gómez, 2014). En otras regiones, como en Asia, los megaproyectos hídricos, incluyendo presas y trasvases, también han generado contestación social (Nüsser, 2013).

La producción de agua desalinizada se ha convertido en un motivo de controversia política y, además, no se ha llevado a cabo un balance técnico, económico ni ambiental acerca de cómo puede intervenir esta fuente no convencional en la gestión de episodios de sequías o para atender posibles incrementos de la demanda hídrica. Según March (2010), el uso y manejo del agua es la ideología más compartida en la planificación y en los recursos hídricos en España. Por ello, el agua debería entenderse como un bien público, pero también se le debería otorgar un valor económico (Bakker, 2002). Cabe hacer notar que, en la cuenca mediterránea, la desalinización ya constituye la principal fuente de abastecimiento de muchos espacios insulares y que en países como Israel se ha erigido también como fuente básica en el suministro urbano (Feitelson y Rosenthal, 2012). En el sureste español, área beneficiada por el trasvase del Ebro que planteaba el PHN (2001), la desalinización ha suscitado un intenso debate no exento de polémica ni de opiniones encontradas, con argumentos a favor y en contra. Tradicionalmente, la política del agua en España se ha 
basado en el desarrollo de grandes infraestructuras, como embalses, trasvases y, recientemente, plantas desalinizadoras (Swyngedouw, 2016). La apuesta por esta nueva fuente alternativa se vincula al debate que, desde mediados de la década de 1990, se establece entre aquellos que postulaban por la continuidad del denominado paradigma hidráulico y los que abogaban por la necesidad de realizar un cambio en las políticas hidráulicas (Saurí y Del Moral, 2001; Del Moral, 2010). Debate que se prolonga hasta la actualidad y que se ha dejado notar en profundas tensiones entre partidos políticos y comunidades autónomas cedentes y receptoras de caudales a través de trasvases hídricos (Uche y Valero, 2001; Albiac et al., 2007).

La apuesta por la desalinización a través del Programa A.G.U.A. (2004) (Actuaciones para la Gestión y Utilización del Agua), para sustituir en parte las aportaciones del controvertido trasvase del Ebro, además de significar una prolongación del llamado "paradigma hidráulico tradicional» y de las viejas políticas de oferta de agua, tampoco ha tenido un tratamiento adecuado en los dos ciclos de planificación que se han completado conforme a la Directiva Marco del Agua (2000), aunque sí que ha habido algunos avances con determinaciones que vinculan estos recursos no convencionales, con la mejora de la calidad de las masas de agua. El segundo ciclo de planificación, para el periodo 2015-2016, de las demarcaciones hidrográficas del Júcar y el Segura, se aprobó con el Real Decreto 1/2016, de 8 de enero, si bien, en materia de desalinización, la revisión de dichos planes de cuenca apenas incorporan información adicional a la contenida en los planes aprobados en 2014, en el primer ciclo de planificación (2009-2015). A pesar de su trascendencia, el apartado de recuperación íntegra de costes no ha sido tratado de forma adecuada, ni en usos urbanos ni en agrícolas. Así, apenas se ofrecen datos sobre los costes reales de las distintas desalinizadoras en comparación con otras fuentes de recursos, ni de su repercusión en los usuarios, si bien, en el caso de la demarcación del Segura, la revisión de su plan hidrológico apunta a una cuestión de primer orden, como es la necesidad de aplicar una exención de la amortización de estas infraestructuras hidráulicas. Y ello se justificaría con la propia Directiva Marco del Agua, ya que un mayor aprovechamiento de las desalinizadoras facilitaría la sustitución de extracciones en acuíferos sobreexplotados. Sin embargo, en los respectivos planes revisados del Júcar y del Segura, se admite la opción de que una parte de los recursos generados por la desalinización pudieran atender futuros incrementos de la demanda urbano-turística, mientras se prohibiría la creación de nuevos regadíos.

El objetivo de esta investigación es hacer una revisión del estado actual de la producción de agua desalinizada en España con manejo de la escala estatal y regional. A partir de datos de producción y explotación actualizados, se ofrece un balance de las ventajas y de los inconvenientes de la desalinización en las regiones de Valencia y Murcia, especialmente los relacionados con los costes económicos y energéticos, aunque también se tendrán en cuenta factores socioterritoriales y ambientales. Esta fuente no convencional ha tenido un fuerte impulso durante los dos últimos años, a raíz de la intensa sequía que padecen 
las cabeceras del Tajo, del Segura y del Júcar. Descartadas o reducidas otras alternativas en los nuevos ciclos de planificación hidrológica (2009-2015 y 2015-2021), como los trasvases, los mercados de agua y el empleo de recursos alternativos (pluviales y residuales depuradas), se hace necesario revisar el debate sobre las ventajas y las desventajas de la desalinización como alternativa típicamente "hidráulica» para garantizar suministros urbanos, turísticos e incluso agrícolas, apostando por "tarifas subvencionadas» al amparo de los decretos de sequía.

Metodológicamente, se han consultado diferentes fuentes oficiales (Ministerio de Medio Ambiente, Confederaciones Hidrográficas, Comisión de Precios, etc.), investigaciones previas y, como valor añadido del trabajo, se manejan datos actualizados facilitados directamente por las empresas que se encargan de la gestión de las desalinizadoras en el sureste español. Con esa información, se ha elaborado una base de datos con todas las grandes plantas construidas durante las dos últimas décadas en las regiones de Valencia y Murcia con el Plan Hidrológico Nacional (2001) y con el Programa A.G.U.A. (2004), y también de otras 23 desalinizadoras de agua marina y salobre continental de menor capacidad (Abad y Moreno, 2015) que garantizan suministros urbanos y turísticos en el litoral valenciano. De todas ellas, se dispone de datos de diseño, explotación, gestión, producción, costes, etc., que resultan de gran interés para elaborar una cartografía de la ubicación de dichas plantas, así como de las áreas y de los usos destinados y, sobre todo, para valorar la fuerte expansión que ha tenido la desalinización en el levante y en el sureste ibérico.

La investigación se ha estructurado en dos grandes apartados. En primer lugar, se revisan y se analizan los datos de la capacidad de producción de agua desalinizada y su evolución, atendiendo a dos escalas de análisis: en España y en las regiones de Murcia y Valencia. Finalmente, se expone un debate sobre las ventajas y las desventajas de este nuevo recurso, así como las conclusiones del trabajo, incluyendo una reflexión en torno a la importancia que puede adquirir esta fuente no convencional en las regiones del sureste ibérico como un recurso para garantizar distintos usos, principalmente urbano-turísticos, a fin de reducir su vulnerabilidad frente a los riegos de sequía.

\section{Producción y consumo de agua desalinizada}

\subsection{El agua desalinizada en España. Evolución y situación actual (1965-2016)}

España se sitúa como el primer país europeo en producción anual de agua desalinizada y el tercer país del mundo en capacidad de generación (Cajigas, 2012). En relación con el número de plantas, España ocupa el quinto lugar del mundo, con un total de 900 plantas que tienen una capacidad de producción de $1.100 \mathrm{hm}^{3} /$ año (Morote et al., 2017). Como indica López (2009), España constituiría un ejemplo perfecto del control del aprovechamiento y la planificación de los recursos hídricos. Control articulado a través de complejos y costosos sistemas de ingeniería hidráulica y centralizado en diferentes formas 
de gobernanzas del agua (Saurí y Del Moral, 2001; Bakker, 2002) que dejan una impresión muy perceptible en el paisaje (Swyngedouw, 2013). La desalinización, igual que ocurre en otros proyectos de ingeniería tradicional a gran escala, como los trasvases de agua, puede ser considerada una fuente de suministro típicamente hidráulica que sirve para atender la demanda en escenarios de fuerte incremento del consumo agrícola, urbano y turístico (March et al., 2014; Swyngedouw, 2015).

Según advirtieron Rico et al. (1998), en España, ya en el año 1996, la capacidad de producción de agua desalinizada alcanzaba la cifra de 500.000 $\mathrm{m}^{3} /$ día (182,5 hm³/año), el $60 \%$ de la cual se concentraba en las Islas Baleares y en Canarias. Además de estos espacios insulares, otras áreas españolas donde la desalinización llegó a ser importante en la década de 1990 y principios del 2000 fue la costa de Málaga y la zona atendida por la Mancomunidad de los Canales del Taibilla (en adelante MCT), en Murcia y Alicante (March et al., 2014). En España, según puso de manifiesto el Ministerio de Medio Ambiente a principios de la década del 2000 , la desalinización alcanzaba una producción de unos $220 \mathrm{hm}^{3} / \mathrm{año}, 127 \mathrm{hm}^{3}$ (el 57,72\%) de los cuales eran proporcionados por el tratamiento de agua salobre y $93 \mathrm{hm}^{3}$ (el 42,27\%), de agua de mar. Del total de agua desalinizada, un $72 \%$ se utilizaba para uso urbano e industrial y el resto para regadío. Según Prats (2004), en el año 2000, el conjunto de la utilización de aguas salobres y de mar suponía en España una aportación al ciclo hidrológico de unos $250 \mathrm{hm}^{3} /$ año. El 46,8\% de ellos correspondía a agua de mar y el resto, a agua salobre. El desarrollo de las técnicas de desalinización, y especialmente aquellas más eficientes que requieren un menor consumo energético, han contribuido a mejorar el rendimiento de estas operaciones, puesto que se ha alcanzado un menor coste de producción.

A finales de la pasada centuria, y antes del fuerte impulso oficial de la desalinización que recogieron tanto el Plan Hidrológico Nacional (2001) como el Programa A.G.U.A. (2004), ya existían 600 minidesalinizadoras instaladas en el sureste ibérico, un tercio de las cuales eran ilegales, al no estar registradas y carecer del permiso necesario para realizar el vertido de la salmuera (Olcina y Moltó, 2010). En el año 2000, otras estimaciones valoraban que la desalinización de agua salobre $\left(132 \mathrm{hm}^{3} /\right.$ año $)$ y de mar $(117 \mathrm{hm} / 3$ año $)$ supondría una aportación al ciclo hidrológico de unos $250 \mathrm{hm}^{3} /$ año, lo cual convertiría a España en la quinta o sexta potencia a escala mundial en ese campo. Por su parte, con las previsiones de ejecución de todos los proyectos de construcción de nuevas plantas desalinizadoras que se estaban desarrollando entre 2000 y 2003, al amparo del Plan Hidrológico Nacional, la producción de agua desalinizada se habría duplicado, al incorporarse otros $266 \mathrm{hm}^{3} /$ año (Prats, 2004). Según los datos facilitados por el Instituto de Comercio Exterior (2007), la capacidad de producción en dicho año era de $1,5 \mathrm{hm}^{3} /$ día $(547,5 \mathrm{hm} /$ año $)$ que se podrían generar en 900 instalaciones, es decir, tres veces más que en 1996 y el doble que a principios del 2000.

Es de notar que los datos oficiales que ofrecía el Ministerio de Medio Ambiente, en 2009 elevaban la capacidad de producción instalada a 2,7 hm²/día 
(985 hm³/año). El 70\% de este volumen corresponde a la desalinización de agua marina y el $30 \%$ al tratamiento de aguas salobres continentales. Aunque el volumen de agua generada apenas representa el 3\% del consumo total efectivo de agua en España, comienza a ser significativo si se tiene en cuenta el gasto urbano de agua, ya que, para el año 2010, suponía un $13 \%$ del consumo hídrico en las ciudades y estaba previsto que este porcentaje alcanzaría el 20\% en 2015, según indicaban Olcina y Moltó (2010). Sin embargo, dicho valor relativo no se ha cumplido debido al descenso apreciable del consumo de agua y la utilización de recursos convencionales, dada la bonanza pluviométrica de los años 2011, 2012 y 2013 (Gil et al., 2015). Con datos de 2014, según la Asociación Española de Desalación y Reutilización (AEDyR), existen en España 900 plantas desalinizadoras, tanto de agua salobre como de mar, cuyos tamaños oscilan entre 100 y más de $100.000 \mathrm{~m}^{3} /$ día de capacidad de producción. Según esta asociación, también se destaca que, en España, desde la década de 1970, se viene utilizando la producción de agua desalinizada, que, en la actualidad, alcanza una capacidad aproximada de 1,2 millones de $\mathrm{m}^{3} /$ día (438 hm³/año), de los cuales $700.000 \mathrm{~m}^{3} /$ día corresponden a la desalinización de agua de mar (el 58,33\%) y el resto, a la de agua salobre (acuíferos).

El mayor impulso a la desalinización en España tuvo lugar a partir de la aprobación de la Ley 10/2001, de 5 de julio, del Plan Hidrológico Nacional, y con el Programa A.G.U.A. (2004) que desarrolla la Ley 11/2005, de 22 de junio, por la que se modifica la Ley 10/2001, de 5 de julio, del Plan Hidrológico Nacional. El Plan Hidrológico Nacional (2001) hizo suyas las peticiones de los distintos planes hidrológicos de cuenca, recogiendo numerosas actuaciones en materia de abastecimientos de agua potable, si bien la mayoría eran de perfil marcadamente hidráulico, con inversiones dirigidas a crear nuevos embalses, conducciones de captación y transporte, potabilizadoras, depuradoras, reutilización de aguas residuales, transferencias de agua y desalinizadoras.

No obstante, el mayor impulso oficial a la construcción de plantas desalinizadoras debe vincularse con a la promulgación del Programa A.G.U.A. en 2004 (Real Decreto Ley 2/2004, de 18 de junio). Este programa surgió repentinamente, después del acceso al poder del Gobierno socialista tras las elecciones generales de marzo de 2004, como nueva política hidráulica en las cuencas del Mediterráneo que iban a ser beneficiadas por el trasvase del Ebro contemplado en la Ley del Plan Hidrológico Nacional (Ley 10/2001). Dicho programa se presupuestó inicialmente en 1.191 millones de euros, con un plazo de ejecución de cuatro años. Uno de los ejes centrales del Programa A.G.U.A. era la sustitución de $1.050 \mathrm{hm}^{3}$ previstos en el trasvase del Ebro con los recursos proporcionados por la desalinización de agua marina. Además, garantizaba, junto con las plantas desalinizadoras previstas en el PHN y otras actuaciones en mejora de infraestructuras hidráulicas, los recursos hídricos precisos para el abastecimiento de los 79 municipios integrados en la MCT (March et al., 2014). La versión inicial del Programa A.G.U.A. preveía 41 actuaciones en la Comunidad Valenciana, que luego fueron ampliadas a 52 en la tramitación parlamentaria de la Ley 11/2005. Debe subrayarse que muchas 
de estas obras figuraban ya en el anexo de inversiones de la Ley 10/2001 del Plan Hidrológico Nacional, como actuaciones complementarias para atender a problemas locales. El coste total relacionado con la desalinización ha supuesto una inversión pública cercana a 1.100 millones de euros, de los cuales más de 200 millones han sido aportados por la Unión Europea (FEDER y Fondos de Cohesión), mientras que la inversión restante procede de fondos propios y préstamos suscritos por la sociedad estatal Acuamed (Aguas de las Cuencas Mediterráneas, SA).

\subsection{La producción de agua desalinizada en las regiones de Murcia y Valencia. Exceso de oferta y consumo dependiente de ciclos de sequía}

En las regiones de Murcia y Valencia hay construidas 17 grandes plantas desalinizadoras con una capacidad de $442 \mathrm{hm}^{3} / \mathrm{anno}$. En Murcia (8 plantas), destaca la desalinizadora de la Virgen de los Milagros (Mazarrón), por ser la primera en construirse en 1998. En la Comunidad Valenciana, con un total de 9 grandes plantas, es Alicante la provincia donde se encuentra el mayor número de ellas (6): Torrevieja, Alicante I y Alicante II, Muchamiel, Denia-Racons y Jávea. Por lo que se refiere al resto de provincias valencianas, vemos que, en Castellón, se finalizaron dos plantas en los últimos años (Oropesa del Mar y Moncófar) y, en Valencia, una (Sagunto), si bien ninguna de las tres está en servicio.

En las regiones de Murcia y Comunidad Valenciana, la mayor capacidad de producción de agua desalinizada se concentra en el área atendida por la MCT. Con la construcción de las desalinizadoras propuestas por el Programa A.G.U.A. (San Pedro del Pinatar I y II, y Alicante I y II), se alcanza una capacidad de producción de agua desalinizada de $96 \mathrm{hm}^{3}$, aunque cabe indicar que, desde que se comenzó a desalinizar agua hasta el momento, nunca se ha llegado a producir dicho volumen máximo de recursos. En 2003, cuando se inauguró la planta de Alicante I, el agua total producida solo fue de $5 \mathrm{hm}^{3}$ (el 5,2\% del total de capacidad) (gráfico 1). Al año siguiente, la producción se triplicó, con un total de $16,8 \mathrm{hm}^{3}$ (el 17,5\%), mientras que el máximo histórico de volumen de agua producida se llevó a cabo en los años 2008 y 2009, con 72 hm $^{3}$ en cada año (el 75\%). A partir de esta fecha, tuvo lugar un descenso constante del volumen producido, salvo en el año 2015, que se incrementó debido a la intensa sequía que padecía el sureste español desde finales de 2013. En este sentido, en 2013, solo se desalinizaron $6,2 \mathrm{hm}^{3}$ (el 6,45\%), es decir, se llegó a cifras similares a las del punto de partida (año 2003), pero, en dicho caso, con 4 plantas acabadas. Ello se debió a la disponibilidad de otros recursos convencionales, por ejemplo, los proporcionados por el propio río Taibilla, que, en 2013, alcanzó una aportación total de $72,6 \mathrm{hm}^{3}$, teniendo en cuenta que, en el año anterior, no se llegó a los $50 \mathrm{hm}^{3}$. Por lo tanto, en la MCT, la producción de agua desalinizada se ha visto influenciada por la disponibilidad de sus propios recursos, especialmente del agua procedente del Taibilla y del trasvase del Tajo-Segura. Por ello, se puede apreciar cómo, ante la escasez de recursos convencionales, la producción de agua desalinizada se convirtió en un recurso 
Gráfico 1. Evolución de la producción de agua desalinizada en la Mancomunidad de los Canales del Taibilla en miles de $\mathrm{m}^{3}$ (años 2003-2016).

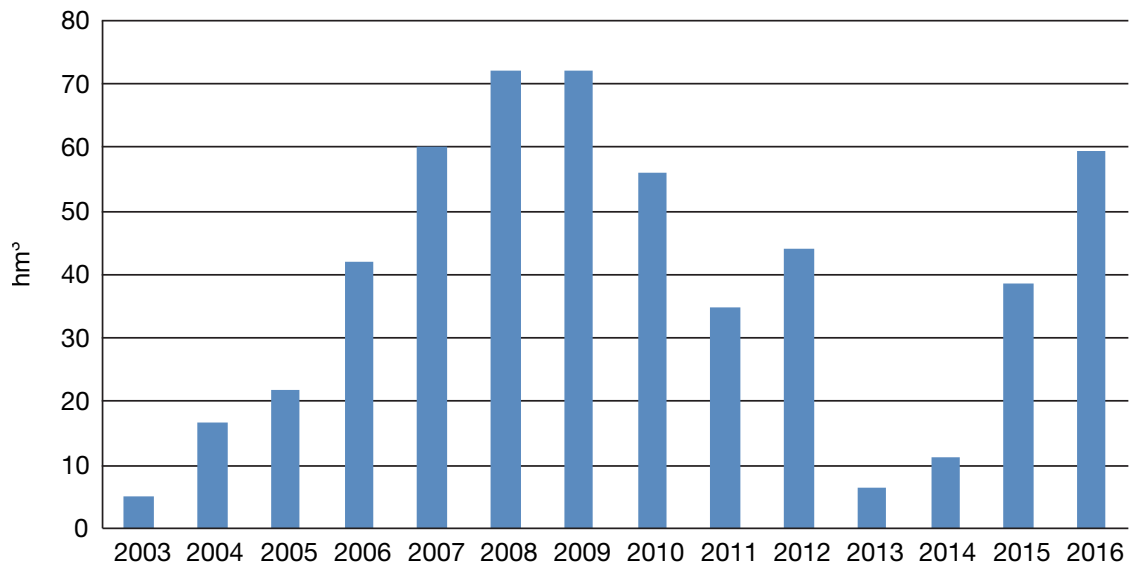

Fuente: Mancomunidad de los Canales del Taibilla (2017). Elaboración propia.

estratégico para paliar el déficit de agua. En este sentido, con datos actualizados de 2016, la producción de agua desalinizada alcanzó los 59,5 hm³.

Como se ha advertido, este descenso se debe a la disponibilidad de otros recursos más abundantes y baratos, como los aportados por el trasvase TajoSegura y los caudales derivados del río Taibilla $\left(72,6 \mathrm{hm}^{3}\right.$ en 2013 frente a los 36 y $47 \mathrm{hm}^{3}$ de 2008 y 2009, respectivamente). El máximo porcentaje de agua desalinizada aportada tuvo lugar en 2009, con el 33,51\% del total de los recursos de la MCT. En 2014, solo representó el 6,13\%, y, en 2015, en cambio, alcanzó el 20,81\% (gráfico 2). En relación con la producción por plantas, las de Murcia

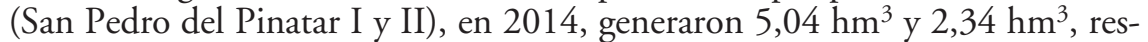
pectivamente, $y$, en $2015,23,20 \mathrm{hm}^{3}$ y $5,02 \mathrm{hm}^{3}$ cada una, mientras que las de Alicante I y II, generaron $2,78 \mathrm{hm}^{3}$ y $1,05 \mathrm{hm}^{3}$ cada una en $2014, \mathrm{y} 7,47 \mathrm{hm}^{3}$ y $2,85 \mathrm{hm}^{5}$ en 2015 . Especialmente, la mayor capacidad de producción se lleva a cabo en los meses estivales, a causa de la mayor demanda para los usos urbanoturísticos. Además, cabe indicar que la de Valdelentisco (Murcia), finalizada en 2008, apenas ha funcionado. Respecto a los datos comentados anteriormente, cabe advertir que la producción de agua en 2016 se ha incrementado por la sequía padecida desde 2014 y los recortes de las transferencias procedentes del Tajo-Segura (Morote et al., 2017).

Si se analiza el estado actual del agua desalinizada por regiones, en Murcia, la capacidad total de producción es de 202,9 $\mathrm{hm}^{3} /$ año, que se reparten para abastecimiento urbano en $132,9 \mathrm{hm}^{3}$ y $70 \mathrm{hm}^{3}$ para riego (tabla 1). El total de inversión realizada asciende a 844 millones de euros, donde destacan las plantas de Águilas (268,3 millones), Valdelentisco (224 millones) y Escombreras (145 millones). Se encuentran en servicio las desalinizadoras de la Marina de Cope 
Gráfico 2. Evolución de los recursos hídricos suministrados por la Mancomunidad de los Canales del Taibilla en miles de $\mathrm{m}^{3}$ (años 1989-2016).

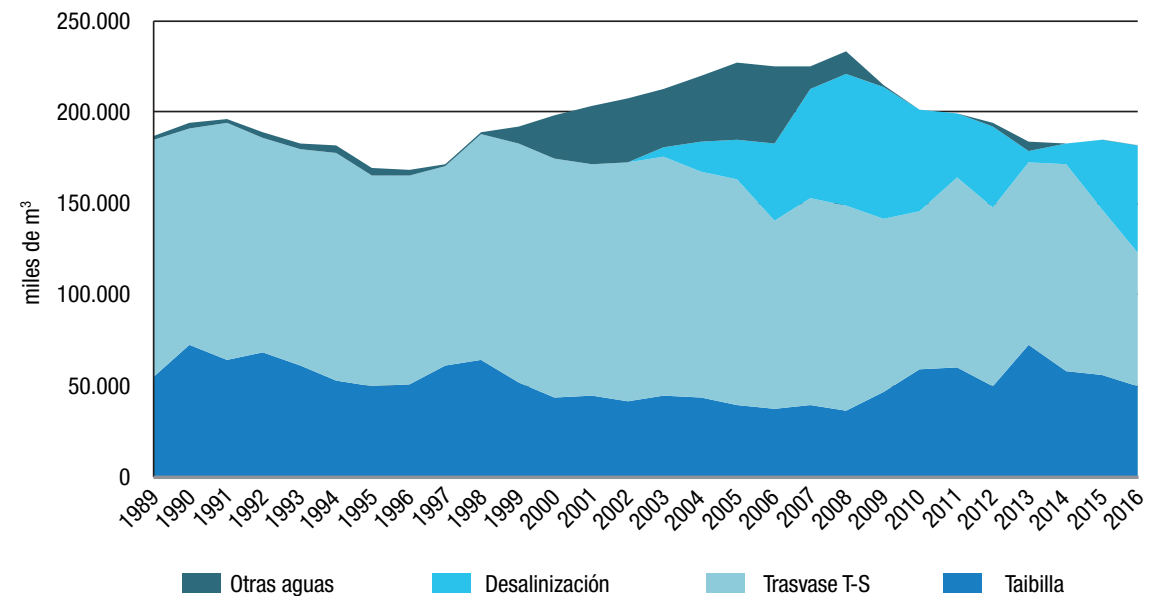

Fuente: Mancomunidad de los Canales del Taibilla (2017). Elaboración propia.

(Águilas), de la Virgen de los Milagros (Mazarrón), de Escombreras (Cartagena), la desalobradora de retornos de riego del Mojón (San Pedro del Pinatar) y las de San Pedro del Pinatar I y II. Si bien, hasta 2015, la mayoría de ellas no tienen ninguna demanda para usos urbano-turísticos, funcionan en verano o bien los fines de semana aprovechando los periodos con tarifas más baratas (de P3 a P6). También cabe indicar la existencia de un nutrido conjunto de pequeñas plantas desalinizadoras de agua salobre en funcionamiento desde hace un par de décadas y localizadas en el Campo de Cartagena (municipios de Cartagena, Mazarrón, San Javier, Torre Pacheco y Los Alcázares).

En este sentido, según la Dirección General de Industria, Energía y Minas del Gobierno regional de Murcia, tenía registradas 28 plantas de tratamiento, con un total de producción de $9,6 \mathrm{hm}^{3} /$ año, y que actuaban principalmente mediante un proceso de ósmosis inversa (Rico et al., 1998). Por lo tanto, si, al total de capacidad de producción de $202,9 \mathrm{hm}^{3} /$ año, se le suma el de estas pequeñas plantas, se llegaría a un total de más de $210 \mathrm{hm}^{3}$. En relación con la desalinización de aguas subterráneas, según indica Rodríguez (2003), desde un punto de vista económico, se debe extraer el agua mediante sondeos y no directamente del mar, pues así sale ya filtrada (sin materia orgánica) y no se necesita realizar un pretratamiento de filtrado, pues encarecería el precio del producto final, ya de por sí elevado. Para ubicar los emplazamientos de captación de forma idónea, lo primero que hay que hacer es elegir preferiblemente los acuíferos costeros con intrusión marina, pues los posibles problemas derivados de la actuación tendrán seguramente menos repercusiones sociales en estos que en otros equilibrados. Además, el hecho de que un acuífero costero muestre un alto 
Tabla 1. Grandes desalinizadoras de la Región de Murcia

\begin{tabular}{|c|c|c|c|c|c|}
\hline Ubicación & $\begin{array}{l}\text { Volumen de } \\
\text { riego }\left(\mathrm{hm}^{3}\right)\end{array}$ & $\begin{array}{c}\text { Volumen de } \\
\text { abastecimiento } \\
\left(\mathrm{hm}^{3}\right)\end{array}$ & $\begin{array}{l}\text { Inversión } \\
\text { en millones } \\
\text { de euros }\end{array}$ & $\begin{array}{c}\text { Año de } \\
\text { construcción }\end{array}$ & Estado actual e incidencias \\
\hline Desalinizadora de Águilas & 48 & 12 & 268,3 & 2011 & $\begin{array}{l}\text { Sin demanda urbano-turísti- } \\
\text { ca. Con tarifas baratas, } \\
\text { se quiere regar el Alto } \\
\text { Guadalentín con un bombeo } \\
\text { de } 380 \mathrm{~m} \text {. }\end{array}$ \\
\hline $\begin{array}{l}\text { Desalinizadora de la Mari- } \\
\text { na de Cope (Águilas) }\end{array}$ & 6 & 0 & 14 & 2006 & $\begin{array}{l}\text { En servicio. El } 60 \% \text { está } \\
\text { financiada por regantes } \\
\text { y el } 40 \% \text {, por el Gobierno } \\
\text { regional y la UE. }\end{array}$ \\
\hline $\begin{array}{l}\text { Desalinizadora de la Virgen } \\
\text { de los Milagros (Mazarrón) }\end{array}$ & 10 & 0 & 1,8 & 1998 & $\begin{array}{l}\text { Gestionada por una empresa } \\
\text { privada. En funcionamiento } \\
\text { continuo durante los meses } \\
\text { de julio y agosto. El resto del } \\
\text { año, funciona los fines de } \\
\text { semana. }\end{array}$ \\
\hline $\begin{array}{l}\text { Desalinizadora de Escom- } \\
\text { breras (Cartagena) }\end{array}$ & 0 & 22,9 & 145 & 2009 & $\begin{array}{l}\text { En servicio. Sin demanda } \\
\text { para usos urbano-turísticos. }\end{array}$ \\
\hline $\begin{array}{l}\text { Desalobradora de retornos } \\
\text { de riego del Mojón (San } \\
\text { Pedro del Pinatar) }\end{array}$ & 6 & 0 & 30 & 2006 & En servicio. \\
\hline $\begin{array}{l}\text { Desalinizadora de } \\
\text { Valdelentisco (Cartagena) }\end{array}$ & 0 & 50 & 224 & 2008 & $\begin{array}{l}\text { Sin funcionar. Sin usuarios } \\
\text { turísticos. }\end{array}$ \\
\hline San Pedro del Pinatar I & 0 & 24 & 72 & 2006 & En servicio. \\
\hline San Pedro del Pinatar II & 0 & 24 & 89 & 2008 & En servicio. \\
\hline Total & 70 & 132,9 & 844,1 & & \\
\hline
\end{tabular}

Fuente: Rico et al. (1998) MAGRAMA, Estudios de viabilidad de las plantas desalinizadoras (1998-2011). Elaboración propia.

contenido en cloruros es la señal, casi inequívoca, de que entre este y el mar existe una conexión hidráulica y que se asegura el éxito en los bombeos. Principalmente, para asegurar la gestión (coger el agua del mar a través de captaciones) y para evitar que se produzcan contaminaciones salinas a otros sondeos preexistentes (tierra adentro del acuífero), hay que situar los sondeos cerca del mar (de 50 a 100 metros de distancia).

En la Comunidad Valenciana, con un total de 9 grandes plantas desalinizadoras, la capacidad total de producción asciende a $201,1 \mathrm{hm}^{3} /$ año, que se reparten en $161,1 \mathrm{hm}^{3}$ para abastecimiento urbano y $40 \mathrm{hm}^{3}$ para regadío. En relación con el gasto de inversión, en dicha región, el coste alcanzaría los 733,8 millones de euros (tabla 2). En la provincia de Alicante, cabe hacer notar la incidencia que tuvo el Plan de Aprovechamiento y Distribución de Aguas Depuradas y Salinas (PAYDES) creado en 1995 ante la penuria hídrica del sur de Alicante, afectado por las intensas sequías de los años noventa. Es un plan cuya aplicación se inició en la Zona Regable de La Pedrera (sur de Alicante), en 
Tabla 2. Grandes desalinizadoras de la Comunidad Valenciana

\begin{tabular}{|c|c|c|c|c|c|}
\hline Ubicación & $\begin{array}{l}\text { Volumen de } \\
\text { riego }\left(\mathrm{hm}^{3}\right)\end{array}$ & $\begin{array}{c}\text { Volumen de } \\
\text { abastecimiento } \\
\left(\mathrm{hm}^{3}\right)\end{array}$ & $\begin{array}{l}\text { Inversión en } \\
\text { millones de } \\
\text { euros }\end{array}$ & $\begin{array}{c}\text { Año de } \\
\text { construcción }\end{array}$ & Estado actual e incidencias \\
\hline $\begin{array}{l}\text { Desalinizadora } \\
\text { de Torrevieja }\end{array}$ & 40 & 40 & 297 & 2010 & $\begin{array}{l}\text { En funcionamiento desde agosto } \\
\text { de } 2015 \text { para paliar la sequía y la } \\
\text { reducción del trasvase Tajo-Segura. }\end{array}$ \\
\hline Alicante I & 0 & 24 & 72 & 2003 & Funciona los fines de semana. \\
\hline Alicante II & 0 & 24 & 109 & 2008 & Sin servicio. \\
\hline $\begin{array}{l}\text { Desalinizadora } \\
\text { de Muxtamel }\end{array}$ & 0 & 18 & 90 & 2012 & $\begin{array}{l}\text { En funcionamiento desde junio de } \\
2015 \text { para compensar las transfe- } \\
\text { rencias de la MCT al Consorcio de } \\
\text { Aguas de la Marina Baja. }\end{array}$ \\
\hline $\begin{array}{l}\text { Desalinizadora } \\
\text { de Jávea }\end{array}$ & 0 & 9,4 & 24 & 2002 & $\begin{array}{l}\text { En pleno funcionamiento sus cuatro } \\
\text { bastidores. Con su funcionamiento } \\
\text { se está evitando la sobreexplota- } \\
\text { ción de acuíferos. En invierno, fun- } \\
\text { ciona al } 25 \% \text { y, en verano, al } 50 \% \text {. }\end{array}$ \\
\hline $\begin{array}{l}\text { Desalinizadora } \\
\text { de Denia-Racons }\end{array}$ & 0 & 8,3 & & 1991 & En servicio. \\
\hline $\begin{array}{l}\text { Desalinizadora } \\
\text { de Oropesa } \\
\text { del Mar }\end{array}$ & 0 & 18 & 55,4 & 2011 & $\begin{array}{l}\text { Convenios firmados con ayunta- } \\
\text { mientos. Sin demanda por paraliza- } \\
\text { ción de proyectos urbanísticos. }\end{array}$ \\
\hline $\begin{array}{l}\text { Desalinizadora } \\
\text { de Moncófar }\end{array}$ & 0 & 11 & 49,1 & 2012 & $\begin{array}{l}\text { Convenios firmados con ayunta- } \\
\text { mientos. Sin demanda por paraliza- } \\
\text { ción de proyectos urbanísticos. }\end{array}$ \\
\hline $\begin{array}{l}\text { Desalinizadora } \\
\text { de Sagunto }\end{array}$ & 0 & 8,4 & 37,3 & 2011 & $\begin{array}{l}\text { Convenio firmado con el Ayunta- } \\
\text { miento, pero sin demanda urbana } \\
\text { ni industrial. }\end{array}$ \\
\hline
\end{tabular}

\begin{tabular}{llll}
\hline Total & 40 & 161,1 & 733,8
\end{tabular}

Fuente: Rico et al. (1998); MAGRAMA, Estudios de viabilidad de las plantas desalinizadoras (1991-2012); Estudio de Viabilidad del Consorcio de Abastecimiento de los Municipios de la Marina Alta (CASAMA) (2014); Planes Hidrológicos de las Cuencas del Júcar y Segura (2014). Elaboración propia.

contacto con la Región de Murcia, con el objetivo de incrementar los recursos hídricos disponibles de la zona para regadío. Se construyeron un total de 16 pequeñas desalinizadoras en la comarca de la Vega Baja, con un total de producción de $16,2 \mathrm{hm}^{3}$ /año para regadío de unas 10.000 ha (Rico et al., 1998). A las ya mencionadas de Alicante I y II (gestionadas por la MCT), se suman las de Torrevieja, Muchamiel, Jávea y Denia (tabla 2). La de Torrevieja, finalizada en 2010, entró en funcionamiento en el mes de agosto de 2015, con una capacidad de producción de $30 \mathrm{hm}^{3} /$ año (el $40 \%$ de su capacidad) para regadío. Utiliza la tecnología de ósmosis inversa y tiene una capacidad de producción de $80 \mathrm{hm}^{3} /$ año con posibilidad de ampliación a $120 \mathrm{hm}^{3} /$ año, lo que la ha convertido en la más grande de Europa y la segunda del mundo hasta hace un par de años. El coste de la instalación asciende a 297 millones de euros (el 16,83\% aportados por la Unión Europea), con lo que se convierte 
Mapa 1. Principales plantas desalinizadoras en las regiones de Murcia y Valencia.

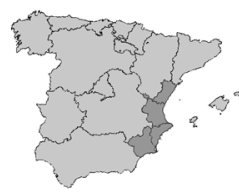<smiles>Nc1scnc1P</smiles>

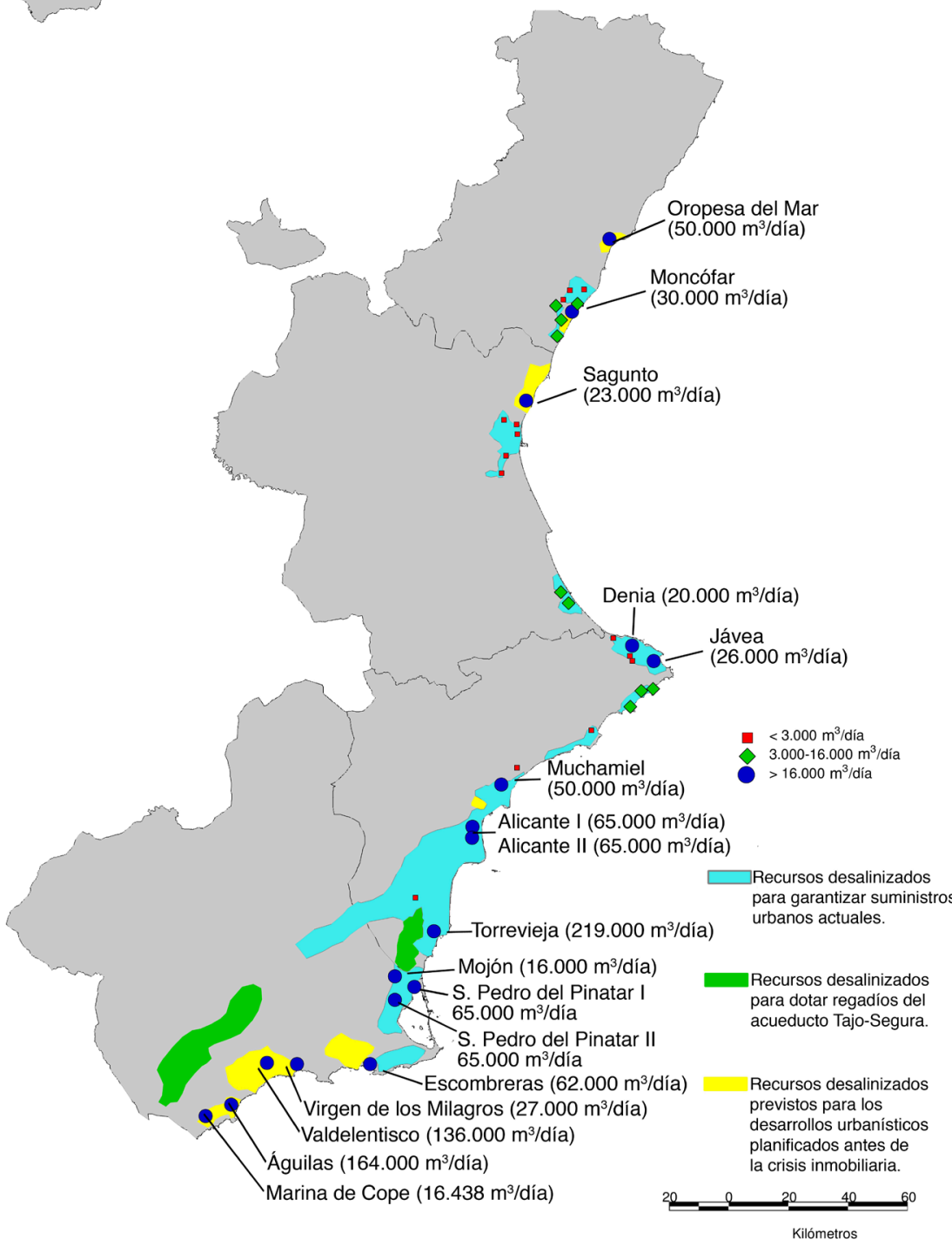

Fuente: MAGRAMA, Estudios de viabilidad de las plantas desalinizadoras (1991-2012); Mancomunidad de los Canales del Taibilla (2015); Planes Hidrológicos de las Cuencas del Júcar y Segura (2014); Comisión de Precios, GV (2015). Elaboración propia. 
en la inversión más importante en una sola actuación realizada en la historia de Torrevieja (Pamies, 2012). El objetivo de esta instalación es producir agua desalinizada para el área atendida por la MCT ( $\left.40 \mathrm{hm}^{3} / \mathrm{año}\right)$, así como cubrir el déficit de riego de zonas regables próximas (hasta $80 \mathrm{hm}^{3} / \mathrm{anno}$ ), unas 125.000 ha de regadío (Del Villar, 2014).

La de Muchamiel (acabada en 2012) entró en funcionamiento en junio de 2015, con una capacidad de producción de $5 \mathrm{hm}^{3} /$ año (el $40 \%$ de su capacidad) para compensar el agua transferida de la MCT al Consorcio de Aguas de la Marina Baja. En un futuro, esta planta atenderá al consumo de agua potable del Campo de Alicante y de la Marina Baja. A finales de 2015, el Gobierno inició las expropiaciones de terrenos en Alicante, Muchamiel y El Campello para construir una conexión entre la desalinizadora de Muchamiel y la conducción Rabasa-Fenollar-Amadorio, con una inversión de 4 millones de euros amparada por el decreto de sequía (Benito, 2015). La idea evidente es asegurar el suministro de agua para el sector turístico de la Costa Blanca, especialmente para Benidorm, acuciado por la coyuntural sequía actual, pero con la idea evidente de no tener que depender de otros recursos externos. Tiene una capacidad de producción de $18 \mathrm{hm}^{3} /$ año para abastecer a la población —unos 443.261 habitantes (Del Villar, 2014) —, aunque esta cantidad se prevé que llegue a los $28 \mathrm{hm}^{3}$ cuando se completen las dos fases proyectadas.

La desalinizadora de Denia-Racons (comarca de la Marina Alta) destaca por ser la primera gran planta construida en la Comunidad Valenciana (año

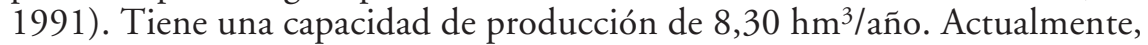
dicha planta se encuentra al $27,3 \%$ de su producción. En esta comarca, también cabe indicar la planta de Jávea, construida en 2002 y con una inversión total de 24 millones de euros. Tiene una capacidad de producción de $9,8 \mathrm{hm}^{3} /$ año, pero actualmente está produciendo alrededor de $3,10 \mathrm{hm} /$ año (el 31,63\%) y está paliando la sobreexplotación de acuíferos costeros. Estas son, en gran medida, las grandes desalinizadoras de la provincia de Alicante, pero cabe poner de relieve que hay un número considerable de pequeñas plantas, entre las que destacan las de la comarca de la Marina Alta, con un total de 10. Además, a las ya mencionadas de Denia-Racons y Jávea, se les unen otras 8 que tratan aguas subterráneas salobres, con un total de producción potencial de $11,95 \mathrm{hm}^{3} /$ año, si bien, a día de hoy, producen alrededor de $4,54 \mathrm{hm}^{3} /$ año (el 37,99\%).

En la provincia de Valencia, solo destaca la planta de Sagunto, finalizada en 2011, pero actualmente se encuentran sin funcionar. Dicha planta costó 37,3 millones de euros y tiene una capacidad de producción de $8,4 \mathrm{hm}^{3}$. Con esta planta, se preveía abastecer la demanda industrial de la Plana de Sagunto e incrementar la garantía y sustituir los bombeos de la masa de agua subterránea. En la provincia de Castellón, se localizan 2 plantas, la de Oropesa del Mar (2011) y la de Moncófar (2012). El coste total invertido ha sido de más de 100 millones de euros entre las dos. Actualmente, se encuentran sin funcionar y tienen una capacidad total de producción anual para abastecimiento urbano de $18 \mathrm{hm}^{3}$ y $11 \mathrm{hm}^{3}$, respectivamente. 
En relación con la planta de Oropesa del Mar, está declarada de interés general y de ejecución prioritaria y urgente por la Ley 11/2005, de 22 de junio, por la que se modifica la Ley 10/2001, de 5 de julio, del Plan Hidrológico Nacional. Tal y como se recoge en el Programa de Medidas del Plan Hidrológico de la cuenca del Júcar, los recursos aportados por esta planta servirán para incrementar la garantía del suministro urbano, tanto en cantidad como en calidad, además de contribuir a la mejora del estado cuantitativo de las masas de agua subterránea asociadas. Las obras incluyen la distribución hídrica a los municipios de Cabanes, Oropesa y Benicasim. Igual que sucede con la planta de Muchamiel, estas se construyeron para garantizar el suministro de numerosos planes urbanísticos en desarrollo que había a principios de la década del 2000. Ello debe vincularse con la Ley 4/2004, de 30 de junio, de Ordenación del Territorio y Protección del Paisaje de la Generalitat Valenciana (derogada por la Ley 5/2014, de 25 de julio, de Ordenación del Territorio, Urbanismo y Paisaje, de la Comunidad Valenciana), que, en el punto 2 del artículo 19 («Uso sostenible del agua»), recogía lo siguiente:

[...] la disponibilidad de recursos hídricos podría ser justificada mediante el compromiso de ejecución, de infraestructuras generadoras de recursos hídricos a través de la aplicación de nuevas tecnologías, como la desalinización de agua de mar o aguas subterráneas salobres, aprovechamiento de aguas depuradas, potabilización o alternativas similares.

En este sentido, las plantas de Castellón iban vinculadas al desarrollo de varios PAI (Programas de Actuación Integrada) y a la construcción de 60.000 viviendas con, al menos, 5 campos de golf. En virtud de los convenios firmados con Acuamed (empresa que gestiona estas dos plantas), los ayuntamientos de Oropesa, Cabanes, Benicasim, Moncófar y Chilches han de pagar las correspondientes tarifas de amortización y explotación de las desalinizadoras, a pesar de que, como consecuencia de la paralización de los planes urbanísticos, no consumen agua desalinizada. Por ejemplo, el Ayuntamiento de Cabanes, que cuenta con un presupuesto de 3,6 millones de euros/año, debe aportar unos 800.000 euros/año para amortizar las desalinizadoras.

\section{Discusión: ¿Una fuente alternativa a los recursos convencionales?}

Las regiones de Murcia y Valencia han experimentado un fuerte incremento de la demanda de agua desde las décadas de 1960 y 1970, en vinculación con la expansión de regadíos hortofrutícolas y con el poblamiento turístico-residencial. Este proceso incrementó la vulnerabilidad de los sistemas de suministro frente a los riesgos de sequía, así como la presión sobre los recursos convencionales, particularmente sobre los ríos alóctonos y acuíferos, abocados muchas veces a régimen de sobreexplotación. En ese contexto, surgieron conflictos territoriales, sobre todo con Castilla-La Mancha, por el aprovechamiento de los ríos alóctonos y por el funcionamiento de transferencias vitales para Murcia 
y Valencia, como son los trasvases Tajo-Segura, Júcar-Turia y Júcar-Vinalopó (Rico, 2010). Por otro lado, la escasez de recursos hídricos, agravada durante situaciones de intensa sequía, ha potenciado numerosas iniciativas vinculadas al empleo de fuentes no convencionales, con la reutilización de aguas residuales regeneradas y desalinización de agua salobre y marina.

A la hora de analizar las ventajas y las desventajas que ofrece la producción de agua desalinizada, cabe tener en cuenta, básicamente, los siguientes aspectos: costes económicos y energéticos, problemas ambientales y finalización de aspectos sociales, territoriales e institucionales. En un ejemplo de mala adaptación técnica, una de las ventajas que ofrece la desalinización es que dicho recurso posibilita paliar los problemas ambientales generados por la sobreexplotación de acuíferos, con secuelas como son la intrusión marina y la contaminación difusa de origen agrícola. Los defensores de la desalinización en España argumentan que la producción de estos recursos puede ser la solución a los problemas de suministro en la costa mediterránea y quizás la clave para facilitar el abastecimiento de los nuevos crecimientos urbanos (Arrojo, 2004). También se puede convertir en un recurso que no dependa de los condicionantes climáticos ni de las variaciones de disponibilidad que ofrecen los recursos de agua continentales (Feitelson y Rosenthal, 2012). Además, podría acabar con los conflictos políticos, sociales e interterritoriales que generan las transferencias hídricas entre regiones receptoras y excedentarias (Saurí, 2003; Downward y Taylor, 2007; Kohlhoff y Roberts, 2007; Morote et al., 2017). En este sentido, cabe recordar las recientes tensiones surgidas y la reaparición, en 2015-2016, de la llamada "guerra del agua» planteada entre Castilla-La Mancha y Murcia y Valencia por el recorte de las transferencias del trasvase Tajo-Segura. Respecto al impacto ambiental de la desalinización, sus secuelas principales son las altas emisiones de $\mathrm{CO}_{2}$ y el vertido del rechazo de salmuera en el medio marino, si bien este problema ha sido paliado con el desarrollo de nuevas técnicas de dilución que evitan daños sobre las praderas de Posidonia oceanica.

En la región valenciana, alrededor de 25 municipios ubicados en planas costeras dependen de desalinizadoras de agua salobre con una capacidad de producción de $50 \mathrm{hm}^{3} /$ año y que proporcionan unos $38 \mathrm{hm} 3 /$ año. En comparación con las desalinizadoras de agua marina, los costes de producción y transporte son sensiblemente inferiores, pero el bombeo de agua salobre para su desalinización puede agravar de forma irreversible los problemas de intrusión marina en acuíferos costeros.

La producción de agua desalinizada de origen marino ofrece mayores ventajas y ha experimentado una fuerte expansión durante las dos últimas décadas, impulsada tanto por las inversiones previstas en el Plan Hidrológico Nacional (2001), como por las actuaciones a gran escala previstas en el Programa A.G.U.A. (2004) para sustituir el trasvase del Ebro a las regiones mediterráneas. Se ofreció como una alternativa de suministro que proporcionaba "más agua, más rápida y más barata» que el indicado trasvase, para atender demandas urbano-turísticas, en imparable expansión durante aquellos años, e incluso para garantizar el suministro agrícola. Se destacaron las ventajas que ofrecía frente 
a la gran obra hidráulica, así como su capacidad para resolver de forma definitiva los problemas de suministro en el litoral mediterráneo español, evitando también los conflictos entre comunidades autónomas cedentes y receptoras de trasvases (Arrojo, 2004; Estevan, 2008). Estos principios inspiraron la versión definitiva del Programa A.G.U.A., plasmada en la Ley 11/2005, de 5 de julio, que modificó la Ley del Plan Hidrológico Nacional, recogiendo una disposición adicional primera que satisfacía las reivindicaciones de Castilla-La Mancha para el cierre progresivo del Acueducto Tajo-Segura, a medida que se fuera incrementando la producción de agua desalinizada en la cuenca del Segura.

Sin embargo, la viabilidad de las desalinizadoras del Programa A.G.U.A. se construyó sobre dos premisas que en ningún caso se han cumplido. En primer lugar, que los costes de producción fueran iguales o inferiores a otras fuentes de suministro y, en segundo lugar, que hubiera crecido el consumo de agua potable por la fuerte expansión de nuevas áreas urbanas y turístico-residenciales (March et al., 2014). Es de notar que el gasto de electricidad ha bajado de $22 \mathrm{kWh} / \mathrm{m}^{3}$ de 1970 a menos de $4 \mathrm{kWh} / \mathrm{m}^{3}$ en 2016, pero, a pesar de este significativo avance en lo que se refiere a eficiencia energética, la desalinización todavía está lejos de las cifras de consumo que ofrecen las fuentes convencionales y los trasvases, como el del Tajo-Segura $\left(1,1 \mathrm{kWh} / \mathrm{m}^{3}\right)$ e incluso el del Ebro, ya descartado, con un gasto medio ponderado de $2 \mathrm{kWh} / \mathrm{m}^{3}$ (Ródenas y Guillamón, 2005).

El gasto teórico de electricidad necesario para desalinizar agua marina, con un porcentaje de recuperación energética del $50 \%$, se ha establecido en $1,06 \mathrm{kWh} / \mathrm{m}^{3}$. Este límite termodinámico ha abierto un campo de innovación tecnológica que podría reducir el consumo de energía a valores cercanos a $1,56 \mathrm{kWh} / \mathrm{m}^{3}$ (Elimelech y Phillip, 2011). Estos avances en eficiencia energética resultan esenciales para reducir la enorme diferencia que todavía separa los costes de producción del agua desalinizada de los recursos convencionales. Es cierto que los costes económicos de la desalinización se han reducido notablemente, puesto que han pasado de los $2 € / \mathrm{m}^{3}$ en 1970 a valores entre 0,90 y $1,1 € / \mathrm{m}^{3}$ en las grandes plantas construidas con el Programa A.G.U.A. (Del Villar, 2014). Comparados con las tarifas del trasvase del Tajo-Segura $\left(0,11 € / \mathrm{m}^{3}\right)$ y con el precio máximo que podrían pagar los regantes de Murcia y Valencia (de 0,20 a $0,30 € / \mathrm{m}^{3}$ ), el agua desalinizada arroja costes de operación y de amortización sumamente elevados que solo pueden asumir los abastecimientos urbanos, y no sin serias dificultades financieras, como las que padece la empresa pública Acuamed, que ha comprometido más de 2.000 millones de euros de fondos estatales y europeos para finalizar las desalinizadoras del Programa A.G.U.A. (Rico, 2014).

El precio del agua desalinizada ha determinado la aparición de usuarios que tienen dificultades para poder acceder a este recurso o incluso que quedan excluidos del mismo, como ciertos usos agrarios y grupos sociales de bajo poder adquisitivo, como ya ha ocurrido, por ejemplo, en áreas de California del Sur (México) (McEvoy, 2014). Entre los primeros, excepto el cultivo de flores en invernadero, el resto de los aprovechamientos de regadío (hortalizas de invierno 
y cítricos) no pueden hacer frente a los costes del agua desalinizada y mantener la viabilidad de sus explotaciones. Entre los segundos, el paulatino y constante incremento del agua en baja en los últimos años se ha traducido en el aumento de la morosidad y el fraude (March et al., 2015).

En regiones vulnerables a la sequía como Murcia y Valencia, cabría potenciar una planificación resiliente del agua, combinando medidas de gestión de la demanda con la optimización de recursos no convencionales. En materia de abastecimientos, se han logrado significativos avances, con la tecnificación de los modelos de gestión en alta y en baja, y con la difusión de medidas y hábitos de ahorro en unidades de consumo del sector doméstico, industrial y comercial, que han reducido los consumos hídricos (Morote et al., 2016). En cambio, en los usos agrícolas, todavía se dispone de cierto margen de actuación en materia de tecnificación de regadíos y de planificación de cultivos, sobre todo en zonas de regadío tradicional del Segura y del Júcar, que tropiezan con dificultades estructurales para introducir sistemas de riego localizado.

Los problemas de escasez de agua, agravados durante situaciones de sequía, intensifican la percepción social de que la planificación hidrológica no está dando una respuesta adecuada a los demandas planteadas por los regantes. Y de ello, como noticia que compromete a la producción y al empleo agrícola, se hacen eco los medios de comunicación, con numerosos artículos, reportajes y entrevistas que han ayudado a construir un discurso reivindicativo y poco favorable a la desalinización. Sin embargo, esta percepción social ha favorecido un mejor posicionamiento de los regantes a la hora de negociar los convenios de explotación de las desalinizadoras en el marco del último decreto de sequía (Real Decreto 356/2015, de 8 de mayo). Algunos medios de prensa de gran proyección en la región de Murcia y Alicante, como es el diario La Verdad, titularon "Acuerdo histórico para abaratar el precio del agua desalada durante la sequía», en una noticia recogida el 15 de octubre de 2015 que explicaba el cierre de una negociación con el Ministerio de Agricultura y Medio Ambiente que había permitido que los regantes accedieran a $50 \mathrm{hm}^{3}$ de agua desalinizada de las plantas de Águilas, Torrevieja y Valdelentisco a un precio de $0,30 € / \mathrm{m}^{3}$.

Por su parte, conviene hacer notar que los decretos de sequía aprobados durante el período 2005-2009, así como el más reciente, de 2016, son instrumentos de planificación hidrológica que se han dirigido a paliar los efectos de la falta de agua, con medidas excepcionales que han potenciado primordialmente las políticas de oferta hídrica sin prestar apenas atención a la gestión de la demanda. En el caso concreto de la cuenca del Segura, esos decretos siempre han estado precedidos de una fuerte reducción de las aportaciones del trasvase Tajo-Segura, aunque las medidas recogidas en ellos ofrecen diferencias de matiz apreciables. El Gobierno anterior, durante la sequía de 2005-2009, recurrió a los artículos 67 a 72 del texto refundido de la Ley de Aguas para hacer posibles los mercados hídricos entre usuarios del Tajo y del Segura, lo que permitió movilizar hasta $70 \mathrm{hm}^{3} /$ año en 2006 y 2007. En cambio, el Gobierno actual, mediante el Real Decreto 356/2015, de 8 de mayo, ha cerrado la opción de los mercados de agua con la cuenca del Tajo, demandada por los regantes del 
Segura, y ha apostado por una política de generación de oferta, con medidas excepcionales que han permitido poner en funcionamiento las desalinizadoras del Programa A.G.U.A.

Por su parte, otro factor decisivo que ha limitado la producción de agua desalinizada durante los últimos años ha sido el fuerte incremento del coste energético provocado por la liberalización del mercado eléctrico acometida en España a partir de 2008, y que ha supuesto un aumento del $75 \%$ en el precio medio de la electricidad, mientras que, en la factura eléctrica, puede suponer más del 50\% del precio final. Estos valores superan con creces los calculados por Acuamed a mediados de la pasada década en las desalinizadoras del Programa A.G.U.A., que oscilaban entre los $0,53 € / \mathrm{m}^{3}$ en la ampliación de la planta de Águilas y los $0,68 € / \mathrm{m}^{3}$ en la planta de Muchamiel. Para atenuar el efecto del incremento de la factura eléctrica, se pueden adaptar los regímenes de producción de las plantas a los contratos de potencia que se formalizan, aprovechando los periodos con tarifas más baratas (de P3 a P6). Sin embargo, la repercusión de los costes de amortización y de explotación de las desalinizadoras se ha dejado sentir en el precio del agua servida en alta por la MCT, que ha crecido de $0,36 € / \mathrm{m}^{3}$ en 2005 a $0,64 € / \mathrm{m}^{3}$ en 2014 , mientras que, a partir del 1 de junio de 2015, se ha incrementado a $0,69 € / \mathrm{m}^{3}$.

Esta última subida, aprobada en marzo de 2015 con una fuerte oposición por parte de los ayuntamientos, ha venido precedida por un notable aumento de la producción de agua desalinizada durante dicho año para suplir la reducción del trasvase Tajo-Segura, motivada por la sequía y por la profunda modificación de las reglas de explotación del acueducto. Estos cambios, recogidos en la Ley 21/2013, de 9 de diciembre, de evaluación ambiental, han elevado el nivel de referencia de excedentes transferidos de 240 a $400 \mathrm{hm}^{3}$ en la cabecera del Tajo, lo que reducirá el funcionamiento del trasvase durante situaciones de sequía, que también suelen afectar simultáneamente a la cuenca del Segura, como está sucediendo actualmente. Además de elevar el nivel 4 de «no trasvase» de $240 \mathrm{hm}^{3}$ a $400 \mathrm{hm}^{3}$, las nuevas reglas imponen un nuevo reparto del agua entre regadíos (75\%) y abastecimientos (25\%), que aseguran al menos $7,5 \mathrm{hm}^{3} / \mathrm{mes}$ al suministro urbano. Sin embargo, este reparto es más favorable a los regadíos y significa, de hecho, que la dotación de $110 \mathrm{hm} 3 /$ año que originariamente se asignó a los abastecimientos que atiende la MCT se reduce a $90 \mathrm{hm}^{3} / a n ̃ o, y$ tendrá que ser suplida durante épocas de falta de agua por una mayor contribución de las desalinizadoras, como ya ocurrió durante la sequía que tuvo lugar en el período 2005-2009 y durante los años 2015 y 2016.

\section{Conclusiones}

El elevado coste de la desalinización ha motivado el rechazo de ayuntamientos y regantes hacia esta fuente no convencional, lo que ha favorecido también una politización del tema (como ha sucedido con otras fuentes hídricas), a raíz de la cual han surgido posturas antagónicas que enfrentan trasvases y desalinizadoras y que ha propiciado una escasa aceptación social del agua 
desalinizada (March et al., 2015). Tras la sequía del período 2005-2009, la producción de agua desalinizada se redujo notablemente por la reducción de la demanda de agua potable, pero también por la bonanza hidrológica que benefició hasta 2013 a las cuencas del Segura, del Júcar y, en menor medida, a la cabecera del Tajo, lo que permitió a los abastecimientos y a los regantes atender a los consumos con recursos convencionales.

Actualmente, la demanda de agua potable no parece que vaya a recuperarse a corto plazo, a causa de las mejoras técnicas introducidas en el suministro en alta y baja y de la consolidación de hábitos de ahorro en el sector doméstico, con incorporación de grifería y electrodomésticos de bajo consumo que permiten alcanzar módulos inferiores a 120 1/habitante/día (Gil et al., 2015; Morote et al., 2016). Además, a pesar de la ligera mejoría económica de los dos últimos años por el buen comportamiento del turismo y por las compras de viviendas por parte de extranjeros en municipios costeros, tampoco parece que la actividad inmobiliaria recupere los niveles anteriores a la crisis de 2007-2008. La consecuencia de ello ha sido un exceso de oferta de agua desalinizada y unas plantas sobredimensionadas, con capacidades de producción muy superiores a las que se precisarían incluso para hacer frente a situaciones de intensa sequía.

La falta de rigor técnico de los informes de viabilidad económica con que se justificaron las desalinizadoras ha provocado, además, un serio problema de orden financiero en el que están implicados el Estado, las comunidades autónomas, los ayuntamientos y las entidades de abastecimiento que suscribieron convenios con Acuamed para hacer uso de agua desalinizada. A ello se une la amenaza de la devolución de los fondos europeos comprometidos en la construcción de las desalinizadoras si estas, finalmente, no entran en funcionamiento, además de la presión que ejercen otros actores decisivos que también tienen intereses comprometidos en las desalinizadoras del Programa A.G.U.A., como son las grandes empresas españolas que han participado en los proyectos de diseño, construcción y explotación de dichas plantas. Tras la paralización del trasvase del Ebro, las mayores empresas de ingeniería, construcción y servicios de agua reorientaron su trabajo al sector de la desalinización. No es casualidad que, en la actualidad, 6 compañías españolas se encuentren entre las 20 mayores del mundo por capacidad de producción de agua desalinizada (March et al., 2014).

El sector de negocio que se generó hace una década no ha cumplido las expectativas iniciales y, lejos de ello, la paralización de la actividad inmobiliaria y la escasa demanda de agua desalinizada por su elevado coste han abocado a la ruina financiera a la mayoría de las grandes plantas construidas. Uno de los casos más llamativos es el ocurrido con la desalinizadora de Escombreras (Cartagena, Región de Murcia), que fue auspiciada por el Gobierno murciano para dotar de agua potable a nuevos complejos residenciales, entre los cuales se incluía la macrourbanización de Novo Carthago, que ha sido investigada por el Tribunal Superior de Justicia de Murcia. La Fiscalía de Medio Ambiente también ha extendido la investigación a la propia desalinizadora de Escombreras, para aclarar el uso de los volúmenes que iba a producir y la viabilidad económica de los contratos suscritos por el Gobierno regional para su construcción 
y explotación. La ejecución del Programa A.G.U.A. no ha sido ajena a la polémica, ni siquiera a las sospechas de corrupción en la concesión de los proyectos de obra. En enero de 2016, fueron detenidos, en el marco de la Operación Frontino, los máximos responsables de la empresa pública Acuamed, entre ellos su director general, junto a ejecutivos de destacadas empresas españolas de ingeniería y construcción, beneficiarias de inversiones del Programa A.G.U.A., por la presunta comisión de delitos de malversación de caudales públicos, tráfico de influencias, cohecho, maquinación para alterar el precio de los contratos, prevaricación y falsedad documental (Hernández, 2016).

En esta encrucijada de intereses, el Gobierno del Estado, en manos del Partido Popular, desarrolló, durante la legislatura 2011-2015, una política del agua de bajo perfil y sin alusión alguna a la recuperación de los trasvases previstos en el Plan Hidrológico Nacional (2001). Incluso ha ido más allá: ha asumido por completo la herencia de los dos gobiernos anteriores del Partido Socialista (2004-2011) en materia hídrica, al finalizar y poner en funcionamiento todas las desalinizadoras del Programa A.G.U.A. Por otro lado, en 2014, y sin apenas modificaciones, aprobó los planes hidrológicos (2009-2015) de las demarcaciones hidrográficas del Júcar, el Segura y el Tajo que el anterior Gobierno no finalizó dentro de los plazos establecidos en la Directiva Marco del Agua 2000/60/CE. Estos nuevos planes, que ya han sido revisados para adaptarse al ciclo de planificación 2015-2021, incluyen normas de enorme repercusión en las regiones de Valencia y Murcia que reducen el funcionamiento de los trasvases Júcar-Vinalopó y Tajo-Segura, cuyas menores transferencias ya están siendo suplidas con agua desalinizada. De hecho, el año 2016 empezó con el cierre temporal del trasvase Tajo-Segura, lo que hace prever que las aportaciones de estas transferencias puedan ser suplidas íntegramente por las desalinizadoras de la MCT y del Programa A.G.U.A.

La apuesta por la desalinización va más allá de considerarla una alternativa estratégica para atender situaciones de sequía y es valorada como una fuente ordinaria de suministro, válida para sustituir extracciones en acuíferos sobreexplotados y para garantizar usos urbanos y agrícolas, sin hacer balance de sus ventajas ni de sus inconvenientes frente a otras fuentes alternativas (intercambio de derechos de uso, aguas regeneradas y pluviales), y sin valorar medidas de gestión de la demanda. La normativa de la Propuesta de Revisión del Plan Hidrológico del Júcar (2015-2021) ha previsto la utilización de 51 hm³/año aportados por las desalinizadoras de Oropesa $\left(18 \mathrm{hm}^{3}\right)$, Moncófar $\left(11 \mathrm{hm}^{3}\right)$, Sagunto $\left(8 \mathrm{hm}^{3}\right)$ y Muchamiel $\left(18 \mathrm{hm}^{3}\right)$. En la propuesta de Plan Hidrológico de la Demarcación del Segura (2015-2021), no se contempla ampliar la capacidad de producción actual ( $334 \mathrm{hm}^{3} /$ año), pero sí su grado de utilización. Se ha previsto que la producción crezca de $156 \mathrm{hm}^{3} /$ año en 2015 a $184 \mathrm{hm}^{3}$ / año en 2021, repartidos en $117 \mathrm{hm}^{3}$ para riego y $67 \mathrm{hm}^{3}$ para uso urbano (Confederación Hidrográfica del Segura, 2014).

La desalinización ha recibido otro espaldarazo significativo en los reales decretos 355/2015 y 356/2015, de 8 de mayo, que declaran la situación de sequía en los ámbitos territoriales de las confederaciones hidrográficas del Júcar 
y del Segura, respectivamente. El ciclo de sequía que se inició en el otoño de 2013 ha abocado a situación de emergencia a los sistemas de explotación alicantinos del Vinalopó-L'Alacantí, Marina Baja y Marina Alta, adscritos a la demarcación del Júcar. $Y$ en serias dificultades se encuentran también los regadíos intensivos que dependen del trasvase Tajo-Segura, que han visto reducidas sus dotaciones de agua por las nuevas reglas de explotación del acueducto (Ley $21 / 2013$, de 9 de diciembre) y por la sequía que también padece la cabecera del Tajo. Durante la última sequía de 2005-2009, el Gobierno anterior promulgó cuatro reales decretos ley sobre medidas urgentes para paliar los efectos de la sequía en determinadas cuencas hidrográficas, que impulsaban la desalinización, la modernización de regadíos y los mercados hídricos con la cuenca del Tajo. En este caso, los contratos de cesión de derechos para el uso del agua se vieron favorecidos con la exención de los gastos fijos y variables de funcionamiento de la tarifa del trasvase, tanto para riego como para abastecimiento. En cambio, los indicados reales decretos de 8 de mayo de 2015 no favorecieron la opción de los intercambios de agua con la cuenca del Tajo ni en la del Júcar.

La piedra angular de las actuaciones que ha impulsado el Gobierno es la desalinización, lo que ha servido para poner en funcionamiento las plantas del Programa A.G.U.A. Por ejemplo, en la Marina Baja, durante el verano de 2015, se descartó la alternativa que ya fue utilizada durante la sequía de 19992002 para transferir agua desde el río Júcar. En su lugar, se optó por la solución más cara de poner en funcionamiento la desalinizadora de Muchamiel para suministrar $5 \mathrm{hm}^{3}$ (a partir del Canal Rabasa-Fenollar-Amadorio) al Consorcio de Aguas de la Marina Baja a un precio cercano a $0,70 € / \mathrm{m}^{3}$.

Para suplir el recorte del trasvase Tajo-Segura, en la demarcación del Segura, el Plan Hidrológico (2015-2021) ha planteado un mayor consumo de agua desalinizada, tanto para riego como para abastecimiento, lo que permitirá aminorar el déficit global de la cuenca de 480 a 400 hm³/año, cuya solución habrá de esperar a la aprobación de un nuevo plan hidrológico nacional. Para suplir la merma de las aportaciones del Tajo-Segura, la MCT tendrá que completar los recursos del trasvase $\left(90 \mathrm{hm}^{3} /\right.$ año $)$ con agua desalinizada $(70 \mathrm{hm} /$ año $)$ y con el río Taibilla ( $40 \mathrm{hm}^{3} / \mathrm{año}$ ). Pero el mayor crecimiento del consumo se produciría en regadío, que haría uso de unos $100 \mathrm{hm}^{3} /$ año proporcionados por las desalinizadoras del Programa A.G.U.A. La "guerra del agua» se ha reavivado con fuerza con Castilla-La Mancha, al recuperar el PSOE el Gobierno regional tras las elecciones autonómicas de 2015, incluyendo la amenaza del cierre del Acueducto Tajo-Segura. En combinación con la sequía y con la reducción del trasvase por efecto de las nuevas reglas de explotación, la "guerra del agua» también ha impulsado las iniciativas para el suministro de agua desalinizada (Benito y Alarcón, 2015).

Sin embargo, la tramitación de dichas solicitudes tropieza con un inconveniente de primer orden, como es la falta de concreción de las tarifas de suministro para uso agrícola o urbano. Lo razonable sería que estas se calcularan a partir de los costes reales de producción y cumpliendo con la premisa de la «Recuperación de los costes de los servicios relacionados con el agua» que pro- 
pugna el artículo 9 de la Directiva Marco del Agua 2000/60/CE. El Gobierno anterior intentó, sin demasiado éxito, suscribir varios convenios con entidades de regantes estableciendo un "precio político» de $0,30 € / \mathrm{m}^{3}$, sin explicar la cuantía de la subvención ni su origen. En el contexto actual de sequía, Acuamed mantiene esa oferta de tarifa, particularmente para la desalinizadora de Torrevieja, que ha entrado en fase de producción y que podría suministrar hasta $40 \mathrm{hm}^{3}$ /año para riego, aunque el Sindicato Central de Regantes del Tajo-Segura sigue sosteniendo que no pueden pagar más de 0,20 o $0,25 € / \mathrm{m}^{3}$ y que no van a renunciar al agua del Tajo a cambio de agua desalinizada. Además, a partir de 2015, las desalinizadoras gestionadas por Acuamed en la MCT tienen la previsión de producir $150 \mathrm{hm}^{3} /$ año para paliar los recortes hídricos de las transferencias del trasvase Tajo-Segura y poner en funcionamiento plantas finalizadas desde hace años con una producción poco significativa.

Sin embargo, y ante la posibilidad de que la sequía se agrave pese a que tras las lluvias del invierno de 2016-2017 dicha sequía se ha reducido, y el trasvase Tajo-Segura siga sin funcionar, todas las propuestas que se barajan apuntan a una solución política que permita subvencionar el precio del agua desalinizada. El Gobierno del Estado ya ha mostrado su conformidad a prorrogar los decretos de sequía del Júcar y del Segura aprobados en mayo de 2015, y también se comprometería a aportar entre 10 y 15 millones de euros para subvencionar el precio del agua desalinizada con destino a riego. Este «precio social» solo se aplicaría al riego, mientras que los abastecimientos habrían de afrontar íntegramente los costes de producción. Los regantes perciben esta medida como un primer paso para establecer una tarifa asumible y definitiva para el agua desalinizada, lo que facilitaría su consumo durante situaciones de sequía. Tras años esperando esta medida, el diario Información, de Alicante, publicaba la siguiente noticia el día 16 de octubre de 2015:

Los 146.000 usuarios del Trasvase Tajo-Segura y más de 200 empresas y cooperativas se beneficiarán de la subvención del precio del agua desalinizada para su uso agrícola. El Gobierno central va a destinar 8 millones de euros para abaratar el coste de un total de $50 \mathrm{hm}^{3}, 30$ procedentes de la planta de Torrevieja (Alicante), para los que se destinarán 6 millones; y los 20 restantes de la de Valdelentisco (Mazarrón), que recibirán una ayuda de 2 millones de euros. El precio acordado, 30 céntimos el metro cúbico para los usuarios del Trasvase y una rebaja de 10 céntimos sobre los contratos ya firmados para el resto, estará vigente mientras dure la sequía. (Benito, 2015)

Es de notar que la opción de subvencionar el agua desalinizada suscita un amplio respaldo político. No obstante, la opción de lograr un "precio social» para el agua desalinizada tiene difícil encaje en el principio de recuperación de costes que propugna la Directiva Marco del Agua 2000/60/CE. También se ha barajado la posibilidad de subvencionar la electricidad que consumen las desalinizadoras o bien recurrir a la generación de energía solar fotovoltaica, que podría reducir el coste de producción en un 40\% (Fundación Desarrollo Sostenible, 2015). Otra de las opciones que también han planteado altos 
funcionarios del Ministerio de Agricultura, Alimentación y Medio Ambiente en algunos foros consistiría en la integración de las desalinizadoras en un sistema global de gestión hídrica. La desalinización formaría parte de un «mix hídrico» constituido por recursos superficiales, subterráneos y aguas residuales regeneradas, que se consumiría y se asignaría a los diferentes usos atendiendo a criterios de disponibilidad, calidad, coste y garantía de suministro. El coste de la desalinización se repercutiría sobre el conjunto de dicho «mix hídrico», lo que podría elevar las tarifas de un 10 a un $20 \%$, pero el agua desalinizada constituiría el factor de garantía de suministro de todo el sistema (IAGUA, 2015).

En las regiones de Murcia y Valencia, la desalinización ha elevado de forma muy notable la garantía de suministro en los abastecimientos de agua potable, sobre todo en las áreas de uso más cercanas a la costa, donde la implantación de nuevos desarrollos urbanos precisará recursos de agua adicionales y una diversificación de las fuentes de suministro como estrategia básica de gestión de sequías. La utilización de la desalinización ha significado, en gran medida, el fin de la escasez «física» de recursos en el litoral mediterráneo. Su uso permitiría generar recursos en abundancia. Sin embargo, diversos autores han empezado a referirse a un nuevo concepto, el de "escasez socio-económica», que vendría definido por la dificultad de acceder a esos nuevos recursos por parte de los usuarios (Meerganz Von Medeazza, 2004; Swyngedouw, 2013; March et al., 2014; March, 2015).

En materia de uso agrícola, su elevado coste introduce una elevada escasez social que impide que se generalice su empleo. Desde un punto de vista económico y ambiental, resulta esencial valorar el binomio formado por el agua y la energía en términos de coste en comparación con otras fuentes de suministro, pero la desalinización podría verse más como una alternativa y como un recurso estratégico para afrontar futuros escenarios de penuria hídrica y resolver conflictos sociales, ambientales, territoriales e institucionales. Sin embargo, resulta oportuno cuestionar la idea de que la desalinización a gran escala constituya una solución tecnológica definitiva para resolver los problemas de escasez de agua en las regiones del litoral mediterráneo español en el siglo XXI, no al menos hasta que se incremente su eficiencia energética y se reduzcan sus altos costes de producción. A partir de un detallado análisis de experiencias internacionales de desalinización, algunos autores argumentan que esta podría convertirse en una estrategia de mala adaptación para hacer frente a los efectos del cambio climático. En dicho sentido, cabe indicar que hay otras alternativas a la desalinización, como son la recolección de aguas pluviales o la utilización de aguas regeneradas depuradas, que pueden constituir recursos más atractivos debido a la implicación, la flexibilidad, un menor coste y un bajo consumo de energía.

\section{Agradecimientos}

Los autores quieren expresar un cordial sentimiento de gratitud a Liana Ardiles (Acuamed y Ministerio de Agricultura, Alimentación y Medio Ambiente), Andrés Martínez, Carlos Conrradi y Antonio Fornés (Mancomunidad de los 
Canales del Taibilla), Emilio Badillo (Comisión de Precios de la Generalitat Valenciana), José Antonio Andújar (Sindicato Central de Regantes del Acueducto Tajo-Segura), Andrés Martínez (Junta Central de Usuarios del Vinalopól'Alacantí), y Francisco Santiago y Jaime Berenguer (Consorcio de Aguas de la Marina Baja).

\section{Referencias bibliográficas}

Abad Moreno, Pascual y Moreno Durá, Amparo (2015). Estudio para la elaboración de una metodología que permita la estimación de los costes de operación de las desaladoras cuyas tarifas están reguladas por la Generalitat Valenciana. Universitat Politécnica de Valencia y Comisión de Precios de la Generalidad Valenciana, 50 p.

AEDyR (2014). Desalación y reutilización [en línea]. Madrid: Asociación Española de Desalación y Reutilización. <http://www.aedyr.com/ficha.php?id=1775>.

Albert, Antoni y Rullán, Onofre (2007). «Nuevo modelo de producción residencial y territorio urbano disperso (Mallorca 1998-2006)». En: 9th International Geocriticism Symposium Porto Alegre [en línea], 28 de mayo a 1 de junio. <http://www. ub.edu/geocrit/9porto/artigues.htm>.

Albiac, José; Hanemann, Michael; Calatrava, Javier y Uche, Javier (2007). «The Rise and Fall of the Ebro Water Transfer». Natural Resources Journal, 3 (46), 727-757.

Arrojo, Pedro (2004). Valoración Económica y Financiera de los Trasvases Previstos en el Plan Hidrológico Nacional Español. Zaragoza: Universidad de Zaragoza. Facultad de Ciencias Económicas y Empresariales. Documento de trabajo.

Asociación Internacional de Desalación (IDA). Disponible en: <http://idadesal. org/>.

Baldwin, Claudia y Uhlmann, Vikki (2010). «Accountability in planning for sustainable water supplies in South East Queensland». Aust. Planner, 47 (3), 191-202.

BAKKeR, Karen (2002). «From state to market?: Water mercantilización in Spain». Environ. Plan. A, 34, 767-790.

Benito, F.J. (2015). «El turismo de la Costa Blanca resuelve con agua desalada la falta de trasvase del Júcar». Información (4 de noviembre). <http://www.diarioinformacion.com/alicante/2015/11/04/turismo-costa-blanca-resuelve-agua/1692723. html>.

Benito, Pilar (2015). «El Gobierno fija en 30 céntimos el precio del metro cúbico de agua desalada para el riego: El Ejecutivo destinó 8 millones de euros a subvencionar $70 \mathrm{hm}^{3}$, de los cuales 50 proceden de Torrevieja». Información [en línea] (16 de octubre). <http://www.diarioinformacion.com/vega-baja/2015/10/16/gobiernofija-30-centimos-precio/1685633.html>.

Benito, P. y Alarcón, M. (2015). «La sequía de la Región “aprieta” a las desaladoras». La Opinión de Murcia [en línea] (22 de agosto) <http://www.laopiniondemurcia. es/comunidad/2015/08/22/sequia-aprieta-desaladoras/671795.html>.

Boelens, Rutgerd; Duarte, Bibiana; Manosalvas, Rossana; Mena, Patricio y Roa Avendaño, Tatiana (2012). "Contested Territories: Water Rights and the Struggles over Indigenous Livelihoods». The International Indigenous Policy Journal [en línea], 3 (3). <http://ir.lib.uwo.ca/iipj/vol3/iss3/5>.

Cajigas, Ángel (2012). «Jornada Ibeoamérica: acción para el agua: Oportunidades de negocio en el sector del agua». En: Congreso Nacional del Medio Ambiente (Conama), Madrid, del 26 al 30 de noviembre. 
Centro de Estudios Hidrográficos (CEDEX) (2004). Disponible en: <http:// www.cedex.es/CEDEX/lang_castellano/>.

Cole, Stroma (2014). «Tourism and water: From stakeholders to right holders, and what tourism business need to do». Journal of Sustainable Tourism, 22 (1), 98-106.

Confederación Hidrográfica del Júcar (2015). Propuesta de Proyecto de Revisión del Plan Hidrológico de la Demarcación Hidrográfica del Júcar: Normativa. Valencia: Confederación Hidrográfica del Júcar.

Confederación Hidrográfica del Segura (2014). Propuesta de Proyecto de Revisión del Plan Hidrológico de la Demarcación Hidrográfica del Segura. Anejo 2: Inventario de Recursos Hidricos. Murcia: Confederación Hidrográfica del Segura.

Domene, Elena y SAurí, David (2006). «Urbanization and water consumption: Influencing factors in the Metropolitan Region of Barcelona». Urban Studies, 43 (9), $1605-1623$.

Downward, S.R. y TAYlOR, R. (2007). «An assessment of Spain's programa AGUA and its implications for sustainable water management in the province of Almería, southeast Spain». Journal of Environmental Management, 82 (2), 277-289.

Elimelech, Menachem y Phillip, William (2011). «The Future of Seawater Desalination: Energy, Technology, and The Environment». Science, 333, 712-717.

Estevan, Antonio (2008). «El desarrollo de la desalación marina en la costa mediterránea». En: Herencias y problemas de la política hidráulica española. Bilbao: Bakeaz. Fundación Nueva Cultura del Agua.

Feitelson, Eran y Rosenthal, Gad (2012). «Desalination, space and power: The ramifications of Israel's changing water geography». Geoforum, 43, 272-284.

FERnández, Santiago y Barrado, Diego (2011). «El desarrollo turístico-inmobiliario de la España mediterránea e insular frente a sus referentes internacionales (Florida y la Costa Azul): Un análisis comparado». Cuadernos de Turismo, 27, 373-402.

Fundación Desarrollo Sostenible (2015). Nace en Murcia la campaña nacional «Riega con el sol» [en línea]. <http://www.fundaciondesarrollosostenible.org/naceen-murcia-la-campana-nacional-riega-con-el-sol/>.

GajA, Fernando (2008). «El tsunami urbanizador de la costa mediterránea». Scripta Nova, 12 (270), 66-75.

García Acosta, Xavier (2014). «Jardines privados y consumo de agua en las periferias urbanas de la comarca de la Selva (Girona)». Investigaciones Geográficas, 61, 55-69.

Gil, Antonio; Hernández, María; Morote, Álvaro Francisco; Rico, Antonio Manuel; Saurí, David y March, Hug (2015). Tendencias del consumo de agua potable en la Ciudad de Alicante y Área Metropolitana de Barcelona, 2007-2013. Hidraqua. Gestión Integral de Aguas de Levante, SA. Universidad de Alicante.

Gil, Antonio y Rico, Antonio Manuel (2007). El problema del agua en la Comunidad Valenciana. Valencia: Fundación Agua y Progreso de la Comunidad Valenciana.

Gössling, Stefan (2015). «New performance indicators for water management in tourism». Tourism Management, 46, 233-244.

Hernández, José Antonio (2016). «El juez implica a "muy altos cargos de Agricultura" en el fraude de Acuamed». El País [en línea] (20 de enero). <http://politica.elpais. com/politica/2016/01/20/actualidad/1453306935_118390.html>.

Hernández, María (2013). «Análisis de los procesos de transformación territorial en la provincia de Alicante (1985-2011) y su incidencia en el recurso hídrico a través del estudio bibliográfico». Documents d’Anàlisi Geogràfica, 59 (1), 105-136.

Hernández, María; Rico, Antonio Manuel y Juárez, Cipriano (2010). «Conflicts over water and land use on the coastline of the region of Valencia: Agriculture 
versus the urban city». En: Brebbia, C.A.; Hernández, S. y Tiezzi, E. (eds.). The sustainable city: Urban regeneration and sustainability. Southampton (Gran Bretaña): WIT Press, 405-417.

Hof, Angela y Wolf, Nils (2014). «Estimating potential outdoor water consumption in private urban landscapes by coupling high-resolution image analysis, irrigation water needs and evaporation estimation in Spain». Landscape and Urban Planning, $123,61-72$.

IAGUA (2015). ¿Trato o truco?: Sombras en la gestión del tratamiento del agua en España [en línea]. <http://www.iagua.es/noticias/espana/rafael-barrera-morcillo/14/12/03/trato-o-truco-sombras-gestion-tratamiento-agua>.

Instituto de Comercio Exterior (2007). Disponible en: <http://www.icex.es/icex/ es/index.html>.

Kaluis, George y Coccossis, Harris (2003). «Managing water for Athens: From the hydraulic to the rational growth paradigm». European Planning Studies, 11 (3), 245-261.

Kohlhoff, Karl y Roberts, David (2007). «Beyond the Colorado River: Is an international water augmentation consortium in Arizona's future?». Arizona Law Review, 49 (2), 257-296.

Latta, Alex y Gómez, Anahí (2014). «Agua y megaproyectos en Latinoamérica: Una introducción». European Review of Latin American and Caribbean Studies / Revista Europea de Estudios Latinoamericanos y del Caribe, 97, 51-54.

«Ley 10/2001, de 5 de julio, del Plan Hidrológico Nacional». Boletín Oficial del Estado [en línea], 161 (6 de julio). <http://noticias.juridicas.com/base_datos/Admin/ 110-2001.html>.

«Ley 11/2005, de 22 de junio, por la que se modifica la Ley 10/2001, de 5 de julio, del Plan Hidrológico Nacional». Boletín Oficial del Estado, 149 (23 de junio).

Loh, Michael y Coghlan, Peter (2003). Domestic water use study: Perth, Western Australia 1998-2001. Perth: Water Corporation.

López, Elena (2009). "Agua para todos: A new regionalist hydraulic paradigm in Spain». Water Alternative, 2, 370-394.

March, Hug (2010). Urban water management and market environmentalism: A historical perspective for Barcelona and Madrid. Bellaterra: Universitat Autònoma de Barcelona. PhD Thesis.

- (2015). «The politics, geography, and economics of desalination: A critical review». WIREs Water [en línea], 2, 231-243. <http://dx.doi.org/10.1002/wat2.1073>

March, Hug; Hernández, María y Saurí, David (2015). «Percepción de recursos convencionales y no convencionales en áreas sujetas a estrés hídrico: El caso de Alicante». Revista de Geografía Norte Grande, 60, 153-172.

March, Hug; Saurí, David y Rico, Antonio Manuel (2014). «The end of scarcity?: Water desalination as the new cornucopia for Mediterranean Spain». Journal of Hydrology, 519, 2642-2652.

McEvoy, Jamie (2014). «Desalination and Water Security: The Promise and Perils of a Technological Fix to the Water Crisis in Baja California Sur, Mexico». Water Alternatives, 7 (3), 518-541.

Meerganz von Medeazza, Gregor (2004). "Water desalination as a long-term sustainable solution to alternative global freshwater scarcity?: A North-South approach». Desalination, 169, 287-301.

Ministerio de Medio Ambiente (2000). Proyecto de Plan Hidrológico Nacional: Documentación Técnica. Madrid: Secretaría de Estado de Aguas y Costas, 5 vols. 
Monreal, Juan (dir.) (2001). Un nuevo mercado turístico: Jubilados europeos en la región de Murcia. Murcia: Universidad de Murcia.

Moral, Leandro del (2009). «New trends in water management, spatial planning and integration of sectorial policies». Revista Electrónica de Geografía y Ciencias Sociales, XIII, 285.

- (2010). «The Hydraulic Paradigm and Production of a New Geography in Spain: Origins and Historical Evolution between the Sixteenth and the Twentieth Centuries». En: Rivers and Society: From Early Civilizations to Moderm Times. Londres: I.B. Tauris, 440-462.

Morales, Alfredo (1997). Aspectos geográficos de la horticultura de ciclo manipulado en España. Alicante: Universidad de Alicante.

Morote, Álvaro Francisco (2014). «Tipologías urbano-residenciales del litoral de Alicante: Repercusiones territoriales». Ciudad y Territorio: Estudios Territoriales, XLVI (181), 431-443.

Morote, Álvaro Francisco y Hernández, María (2016). «Urban sprawl and its effects on water demand: A case study of Alicante, Spain». Land Use Policy, 50, 352-362.

Morote, Álvaro-Francisco, Hernández, María y Rico, Antonio-Manuel (2016). "Causes of Domestic Water Consumption Trends in the City of Alicante: Exploring the Links between the Housing Bubble, the Types of Housing and the Socio-Economic Factors». Water, 8, 374. <http://dx.doi.org/10.3390/w8090374>

Morote, Álvaro-Francisco, Rico, Antonio-Manuel y Moltó, Enrique (en prensa). "Critical review of desalination in Spain: A resource for the future?». Geographical Research. <http://dx.doi.org/10.1111/1745-5871.12232>

Nüsser, Marcus (ed.) (2013). Large Dams in Asia: Contested Environments between Technological Hydroscapes and Social Resistance. Heidelberg: Springer.

Olcina, Jorge (2002). «Planificación hidrológica y recursos de agua no convencionales en España». En: Insuficiencia Hídrica y Plan Hidrológico Nacional. Instituto Universitario de Geografía. Universidad de Alicante. Caja de Ahorros del Mediterráneo, 69-130.

Olcina, Jorge y Moltó, Enrique (2010). «Recursos de agua no convencionales en España: Estado de la cuestión, 2010». Investigaciones Geográficas, 51, 131-163.

Pamies, Manuel (2012). «La desalinizadora más grande de Europa hará las primeras pruebas en enero». Información [en línea] (17 de septiembre). <http://www.diarioinformacion.com/vega-baja/2012/09/17/desalinizadora-grande-europa-haraprimeras-pruebas-enero/1294842.html>.

Piqueras, Juan (2012). Geografía del territorio valenciano: Naturaleza, economia y paisaje. Valencia: Universidad de Valencia.

Prats, Daniel (2004). "Desalación de aguas salobres y de mar como recurso complementario». En: Melgarejo Moreno, J. (ed.). Repercusiones socioeconómicas del Plan Hidrológico Nacional en la Provincia de Alicante. Alicante: Fundación COEPA, 293-321.

Raya, Pedro y Benítez, José (2002). «Concepto y estimación del turismo residencial: Aplicación en Andalucía». Papers de Turisme, 31-32, 67-89.

«Real Decreto Ley 2/2004, de 18 de junio, por el que se modifica la Ley 10/2001, de 5 de julio, del Plan Hidrológico Nacional». Boletín Oficial del Estado [en línea], 148 (19 de junio). <http://noticias.juridicas.com/base_datos/Admin/rdl2-2004.html>. 
Rico, Antonio Manuel (2007). «Tipologías de consumo de agua en abastecimientos urbano-turísticos de la Comunidad Valenciana». Investigaciones Geográficas, 42, 5-34.

- (2010). «Plan Hidrológico Nacional y Programa A.G.U.A.: Repercusiones en las regiones de Murcia y Valencia». Investigaciones Geográficas, 51, 235-267.

- (2014). «La Mancomunidad de los Canales del Taibilla: Un modelo de aprovechamiento conjunto de fuentes convencionales y desalinización de agua marina». En: Olcina Cantos, J. y Rico Amorós, A. Libro jubilar en homenaje al profesor Antonio Gil Olcina. Alicante: Publicaciones de la Universidad de Alicante, 367-394.

Rico, Antonio Manuel; Olcina, Jorge; Paños, Vicente y Baños, Carlos (1998). Depuración, desalación y reutilización de aguas en España. Vilassar de Mar: Oikos-Tau.

Rico, Antonio Manuel; Olcina, Jorge y Saurí, David (2009). "Tourist land use patterns and water demand: Evidence from the Western Mediterranean». Land Use Policy, 26, 493-501.

Ródenas, Miguel Ángel y Guillamón, Juan (2005). «Trasvases y desalación: Tiza y pizarra». Ingeniería y Territorio, 72. Madrid: Colegio de Ingenieros de Caminos, Canales y Puertos.

Rodríguez Estrella, Tomás (2003). «Posibilidades de captación de agua del mar en la Cuenca del Segura, a través de acuíferos costeros con intrusión marina, para ser tratada en plantas desaladoras». Hidropres, 36, 22-33.

SAURí, David (2003). "Lights and shadows of urban water demand management: The case of the metropolitan region of Barcelona». European Planning Studies, $11,229-243$.

SAurí, David y Moral, Leandro del (2001). «Recent developments in Spanish water policy: Alternatives and conflicts at the end of the hydraulic age». Geoforum, 32, 351-362.

Swyngedouw, Erik (2013). «Into the sea: Desalination as hydro-social fix in Spain». Annual Association American Geographers, 103 (2), 261-270.

- (2015). Liquid power: Contested Hydro-Modernities in Twentieth-Century Spain. Cambridge: MIT Press.

- (2016). «From Spain's hydro-deadlock to the desalination fix». Water International, vol. 41 (1), 54-73.

Troy, Patrick y Holloway, Darren (2004). «The use of residential water consumption as an urban planning tool: A pilot study in Adelaide». Journal of Environmental Planning and Management, 47, 97-114.

Uche, Javier y Valero, Antonio (2001). ¿Hasta qué punto es alternativa la desalación? Zaragoza: Universidad de Zaragoza. Centro de Investigación y Recursos Energéticos (CIRCEO).

VerA, José Fernando (2006). «Agua y modelos de desarrollo turístico: La necesidad de nuevos criterios para la gestión de los recursos». Boletín de la Asociación de Geógrafos Españoles, 42, 155-178.

Villar, Alberto del (2014). «El coste energético de la desalinización en el Programa A.G.U.A.». Investigaciones Geográficas, 62, 101-112.

World Commission on Dams (2000). Dams and Development: A New Framework for Decision-making. Londres: Earthscan. 